\title{
Self-renewing resident arterial macrophages arise from embryonic CX3CR1+ precursors and circulating monocytes immediately after birth
}

\section{Citation}

Ensan, Sherine, Angela Li, Rickvinder Besla, Norbert Degousee, Jake Cosme, Mark Roufaiel, Eric A Shikatani, et al. 2015. "Self-Renewing Resident Arterial Macrophages Arise from Embryonic CX3CR1+ Precursors and Circulating Monocytes Immediately after Birth." Nat Immunol (December 7). doi:10.1038/ni.3343.

\section{Published Version}

10.1038/ni.3343

\section{Permanent link}

http://nrs.harvard.edu/urn-3:HUL.InstRepos:23975273

\section{Terms of Use}

This article was downloaded from Harvard University's DASH repository, and is made available under the terms and conditions applicable to Open Access Policy Articles, as set forth at http:// nrs.harvard.edu/urn-3:HUL.InstRepos:dash.current.terms-of-use\#OAP

\section{Share Your Story}

The Harvard community has made this article openly available.

Please share how this access benefits you. Submit a story.

Accessibility 


\section{Self-renewing resident arterial macrophages arise from embryonic $\mathrm{CX}_{3} \mathrm{CR}^{+}$precursors}

and circulating monocytes immediately after birth

Sherine Ensan ${ }^{1, *}$, Angela $\mathrm{Li}^{1, *}$, Rickvinder Besla ${ }^{3, *}$, Norbert Degousee ${ }^{2}$, Jake Cosme ${ }^{2}$, Mark Roufaiel $^{2}$, Eric A. Shikatani ${ }^{3}$, Mahmoud El-Maklizi ${ }^{1}$, Jesse W. Williams ${ }^{4}$, Lauren Robins ${ }^{2}$, Cedric Li $^{2}$, Bonnie Lewis ${ }^{2}$, Tae Jin Yun ${ }^{5}$, Jun Seong Lee ${ }^{5}$, Peter Wieghofer ${ }^{6}$, Ramzi Khattar ${ }^{2}$, Kaveh Farrokhi ${ }^{1}$, John Byrne ${ }^{2,13}$, Maral Ouzounian ${ }^{2,13}$, Caleb C.J. Zavitz ${ }^{2}$, Gary A. Levy ${ }^{1,2}$, Carla M.T. Bauer ${ }^{7}$, Peter Libby ${ }^{8}$, Mansoor Husain ${ }^{2,3,13}$, Filip K. Swirski ${ }^{9}$, Cheolho Cheong ${ }^{5}$, Marco Prinz $^{10}$, Ingo Hilgendorf ${ }^{11}$, Gwendalyn J. Randolph ${ }^{4}$, Slava Epelman ${ }^{1,2,13}$, Anthony O. Gramolini $^{2,12,13}$, Myron I. Cybulsky ${ }^{2,3,13}$, Barry B. Rubin ${ }^{2,13}$ and Clinton S. Robbins ${ }^{1,2,3,13}$

${ }^{1}$ Department of Immunology, University of Toronto, Toronto, ON, Canada. ${ }^{2}$ Toronto Ge neral Research Institute, University Health Network, Toronto, ON, Canada. ${ }^{3}$ Department of Laboratory Medicine and Pathobiology, University of Toronto, Toronto, ON, Canada. ${ }^{4}$ Department of Pathology and Immunology, Washington University School of Medicine, St. Louis, MO, USA. ${ }^{5}$ Laboratory of Cellular Physiology and Immunology, Institut de Recherches Cliniques de Montréal, Montréal, QC, Canada. ${ }^{6}$ Institute of Neuropathology and Faculty of Biology, University of Freiburg, Freiburg, Germany. ${ }^{7}$ Hoffmann-La Roche, pRED, Pharma Research \& Early Development, DTA Inflammation, Nutley, NJ, USA. ${ }^{9}$ Center for Systems Biology, Massachusetts General Hospital, Harvard Medical School, Boston, MA, USA. ${ }^{10}$ Institute of Neuropathology \& BIOSS Centre for Biological Signaling Studies, University of Freiburg, Germany. ${ }^{11}$ Department of Cardiology and Angiology I, Heart Center, University of Freiburg, Freiburg, Germany. ${ }^{12}$ Department of Physiology, University of Toronto, Toronto, ON, Canada.

${ }^{13}$ Peter Munk Cardiac Centre, University Health Network, Toronto, ON, Canada.

Correspondence:

C.S.R. (clint.robbins@utoronto.ca)

Peter Munk Cardiac Centre and Toronto General Research Institute, University Health Network, Toronto Medical Discovery Tower, 101 College St., Toronto, ON M5G1L7; phone, 416-5817510

*authors contributed equally 
Resident macrophages densely populate the normal arterial wall, yet their origins and the mechanisms that sustain them are poorly understood. Using gene expression profiling we show here that arterial macrophages constitute a distinct population among macrophages. Using multiple fate mapping approaches, we show that arterial macrophages arise embryonically from $\mathrm{CX}_{3} \mathrm{CR}^{+}$precursors and postnatally from bone marrow-derived monocytes that colonize the tissue immediately after birth. In adulthood, proliferation rather than monocyte recruitment sustains arterial macrophages in the steady-state and after severe depletion following sepsis. After infection, arterial macrophages return to functional homeostasis rapidly. Finally, survival of resident arterial macrophages depends on a $\mathrm{CX}_{3} \mathrm{CR} 1-\mathrm{CX}_{3} \mathrm{CL1}$ axis within the vascular niche. 
Most tissues of the body harbor resident macrophages. Yet, macrophages are phenotypically and functionally heterogeneous, a reflection of the diversity of tissue environments in which they reside. In addition to maintaining tissue homeostasis and responding to invading pathogens, macrophages contribute to numerous pathological processes, making them an attractive potential target for therapeutic intervention. To do so, however, will require a detailed understanding of macrophage origins, the mechanisms that maintain them, and their functional attributes in different tissues and disease contexts.

Macrophage ontology has long engendered controversy ${ }^{1,2}$. Nevertheless, the concept that tissue macrophages develop exclusively from circulating bone marrow-derived monocytes has prevailed for nearly a half century ${ }^{3}$. Accumulated evidence, however, including recent studies using sophisticated fate-mapping approaches, have determined that some tissue macrophages and their precursors are established embryonically in the yolk sac (YS) and fetal liver before the onset of definitive hematopoiesis ${ }^{4-11}$. Regardless of their origin, tissue macrophages can maintain themselves in adulthood by self-renewal independent of blood monocytes ${ }^{12,13}$.

Gene-expression profiling of macrophage populations from several tissues has established that only a small number of transcripts are expressed by all macrophages ${ }^{14}$, indicating the importance of the context provided by the tissue when studying macrophage function in homeostasis and disease. The normal arterial wall contains many tissue resident macrophages that contribute crucially to immunity, tissue homeostasis and wound healing following injury ${ }^{15}$. However, the regulatory networks, ancestry and mechanisms that maintain arterial macrophages remain unknown.

Using gene expression analysis, we show that arterial macrophages constitute a distinct population among tissue macrophages. Multiple fate mapping approaches demonstrated that arterial macrophages arise embryonically from $\mathrm{CX}_{3} \mathrm{CR}^{+}$precursors and postnatally from bone marrow-derived monocytes that colonize the tissue during a brief period immediately after birth. In adulthood, arterial macrophages were maintained by $\mathrm{CX}_{3} \mathrm{CR} 1-\mathrm{CX}_{3} \mathrm{CL} 1$ interactions and local proliferation without significant further contribution from blood monocytes. Self-renewal also 
sustained arterial macrophages after severe depletion during polymicrobial sepsis, rapidly restoring them to functional homeostasis.

\section{Results}

\section{Phenotype and gene expression profiling of arterial macrophages.}

Flow cytometry-based analysis of single cell suspensions from healthy aortae of 6-8 week old mice revealed that $38 \pm 4 \%$ of all $\mathrm{CD} 45^{+}$leukocytes were macrophages, identified as F4/80 ${ }^{+} \mathrm{CD} 11 \mathrm{~b}^{+}$cells (Fig. 1a). Other myeloid cell populations observed included F4/80 ${ }^{\text {lo }} \mathrm{CD} 11 \mathrm{c}^{+} \mathrm{MHCII}^{+}$dendritic cells (Fig. 1a) and F4/80 ${ }^{\mathrm{lo}} \mathrm{CD} 64^{+} \mathrm{Ly}_{6 \mathrm{C}} \mathrm{hi}^{\mathrm{lo}}$ monocytes (Fig. 1a). Principal component analysis revealed a distinct transcriptome in arterial macrophages, which clustered near other macrophage populations including microglia, alveolar macrophages, and splenic red pulp macrophages, as characterized by the Immunological Genome Consortium (Fig. 1b, Supplementary Fig. 1a) ${ }^{14}$. Stringent comparison of gene-expression profiles among arterial, brain, alveolar and splenic red pulp macrophages revealed 212 transcripts that were at least fivefold higher or lower in arterial macrophages relative to expression in all three of the other macrophage populations (Fig. 1c,d and Supplementary Fig. 1b,c). To gain insight into biological processes, transcripts encoding molecules with annotated functions were grouped according to Gene Ontology (GO) terms. Transcripts that were more abundant in arterial macrophages were enriched for molecular terms including translation and regulation of cell proliferation. The less abundant transcripts yielded GO enrichment of terms including homeostatic process, cell proliferation and macromolecular complex subunit organization (Supplementary Table 1). Flow cytometry analysis of specific cell surface markers confirmed arterial macrophages share features with macrophage populations from other organs as well as express a unique signature. In addition to the core signature macrophage markers CD64, which encodes the immunoglobulin Fc receptor and the tyrosine kinase receptor MerTK ${ }^{16}$, arterial macrophages expressed Lyve-1, CD68, MHCII, CD86, the class A scavenger receptor Msr1, TLR4 and Tim-4 (Fig. 1a,e).

Zbtb46, encoding a member of the transcription factor family BTB-ZF, is selectively expressed in classical dendritic cells $(\mathrm{cDC})^{17,18}$. Analysis of $Z b t b 46^{+/ \mathrm{gfp}}$ mice, in which a GFP reporter cassette replaces exon 2 of the Zbtb46 BTB domain, revealed high expression of Zbtb46 in 
$\mathrm{CD} 11 \mathrm{c}^{+} \mathrm{MHCII}^{+} \mathrm{CD} 11 \mathrm{~b}^{-} \mathrm{cDC}$ of the aorta, liver, lung and brain (Fig. 1f). GFP was undetected in alveolar macrophages and Kupffer cells, but was expressed in microglia and aortic macrophages, albeit lower than in cDC (Fig. 1f). These data extend recent observations that resident macrophages in some tissues express Zbtb46 ${ }^{19}$, and showed that the amount of Zbtb46 expression, as inferred from the GFP reporter, discriminated between macrophages and cDC in the arterial wall. $\mathrm{cDC}$ were also distinguished from macrophages by expression of the integrin alpha X (CD11c) (Fig. 1g).

Intravenous administration of clodronate liposomes depleted blood monocytes, but not aortic macrophages (Supplementary Fig. 1d), indicating that arterial macrophages reside within the vessel wall. To examine the spatial distribution of arterial macrophages in more detail, we dissected the inner intimal and medial layers from the outer adventitia ${ }^{20}$ and assessed the number of macrophages by flow cytometry. The adventitia contained significantly more CD $45^{+}$ leukocytes than the intimal or medial layers of the vessel wall (Supplementary Fig. 1e). Consistent with this observation, macrophage percentage among CD45 ${ }^{+}$cells (Fig. 1h), and number (Fig. 1i) were markedly higher in the adventitia compared to the intima and media layers. We next used confocal microscopy to visualize $\mathrm{CD} 68^{+}$cells in the intima, media and adventitia compartments of the aorta. On average, $29 \pm 1 \%$ of the tissue area within the adventitia stained positive for CD68 (Fig. 1j). In contrast, only $2.0 \pm 0.2 \%$ of tissue area in the intima and media stained positive for CD68 (Fig. 1j). Analysis at various locations in the aorta demonstrated comparable differences in macrophage content within the adventitia and intima and media (Fig. 1j). Consistent with previous studies, CD11 $\mathrm{c}^{+}$DC were most abundant in the intima of the aortic valves and arch (Supplementary Fig. 1f and ${ }^{21,22}$ ). We also detected macrophages in the carotid as well as femoral arteries (Supplementary Fig. 1g), indicating that resident macrophages occupy multiple arterial sites.

\section{Arterial macrophages have embryonic and postnatal origins.}

In many tissues, resident macrophages arise from embryonic precursors before birth ${ }^{5-7,2310,11}$. Similarly, arterial macrophages were observed in the aorta of mice at E16.5 (Fig. 2a). Flow cytometry revealed 2 phenotypically distinct F4/80-expressing cell populations in the developing embryo; $\mathrm{F} 4 / 80^{\text {hi }} \mathrm{CD} 11 \mathrm{~b}^{\text {lo }}$ cells that resembled YS-derived macrophages ${ }^{6}$, and $\mathrm{F} 4 / 80^{\text {int }} \mathrm{CD} 11 \mathrm{~b}^{\text {hi }}$ 
cells that appeared similar in phenotype to c-Myb-dependent fetal liver monocytes ${ }^{7,24}$. At birth, arterial macrophages were predominately $\mathrm{F} 4 / 80^{\mathrm{hi}} \mathrm{CD} 11 \mathrm{~b}^{\text {lo }}$, although this phenotype was transient and by 2 weeks of age the F4/80 $0^{+}$cells in the aortic wall were mainly F4/80 ${ }^{\text {int }} \mathrm{CD} 11 \mathrm{~b}^{\text {hi }}$ (Fig. 2a). The proportion of arterial macrophages among $\mathrm{CD} 45^{+}$cells increased with age (Fig. 2b) and was associated with progressively increased expression of MHCII (Fig. 2c), indicating a postnatal period of maturation.

The extra-embryonic YS is the main hematopoietic site in mice before E10.0 $0^{4,25}$ hematopoiesis supplies erythroid as well as myeloid precursors to the embryo following the onset of blood circulation at $<$ E9.0. Because arteries contained macrophages before birth, we investigated whether YS progenitors contributed to the arterial macrophage pool using pulse labeling of $\mathrm{CX}_{3} \mathrm{CR}^{+}$progenitor cells in the $\mathrm{YS}^{12}$. Female $C X_{3} C R 1^{\mathrm{CreER}}$ mice ${ }^{26}$, which upon exposure to tamoxifen (TAM) express Cre recombinase under the control of the $\mathrm{CX}_{3} \mathrm{CR} 1$ promoter, were crossed to male $\operatorname{Ros} a 26^{\text {Tomato }}$ reporter mice and pregnant animals were injected with a single intraperitoneal dose of TAM at E8.5. This approach induces the preferential and irreversible expression of the $\mathrm{Td}^{\text {tomato }}$ reporter in YS-derived $\mathrm{CX}_{3} \mathrm{CR}^{+}$cells and their progeny. $68 \pm 8 \%$ of brain microglia in $C X_{3} C R I^{\text {creER }} R 26^{\text {Tomato }}$ animals were $\mathrm{Td}^{\text {tom+ }}$ at E16.5, indicating robust labeling efficiency of YS progenitors and their progeny (data not shown). Consistent with the hypothesis that YS progenitors give rise to arterial macrophages during embryogenesis, $>40 \%$ of $\mathrm{F} 4 / 80^{\text {hi }} \mathrm{CD} 11 \mathrm{~b}^{\text {lo }}$ cells in aortae of mice at E16.5 and the day of birth were labeled $\mathrm{Td}^{\text {tom }}+$ (Fig. 2d-f). Importantly, TAM injection labeled macrophages, but not monocytes in fetal liver (Supplementary Fig. 2a), and failed to label F4/80 ${ }^{\text {hi }} \mathrm{CD} 11 \mathrm{~b}^{\text {lo }}$ macrophages in the arterial wall (Fig. 2d). Therefore, $\mathrm{Td}^{\text {tom+ }}$ macrophages likely derive from early YS EMPs independent of a monocyte intermediate. Normalization of arterial macrophage labeling to labeling of microglia $\left(\% \mathrm{Td}^{\text {tom+ }}\right.$ macrophages in the aorta $/ \% \mathrm{Td}^{\text {tom+ }}$ microglia $)$, which are entirely of YS origin ${ }^{5,27}$, indicated that $\sim 60 \%$ of arterial macrophages at birth arise separate from fetal liver hematopoiesis (Fig. 2f).

To address the possibility that fetal monocytes also contribute to the generation of arterial macrophages, we analyzed aortae in Flt $3^{\mathrm{cre}}$ x $\operatorname{Ros}^{\mathrm{mT} / \mathrm{mG}}$ reporter mice. Definitive hematopoietic 
stem and progenitor cells (HSPC) transiently augment FLT3 during differentiation to all hematopoietic lineages ${ }^{44}$. The approach, therefore, allowed us to identify HSPC-dependent $\mathrm{GFP}^{+}$ macrophages (FLT3-Cre ${ }^{+}$) and HSPC-independent $\mathrm{GFP}^{-}$macrophages (FLT3-Cre'). At birth, approximately $10 \pm 1 \%$ and $28 \pm 3 \%$ of $\mathrm{F} 4 / 80^{\text {hi }} \mathrm{CD} 11 \mathrm{~b}^{\text {lo }}$ and $\mathrm{F} 4 / 80^{\text {int }} \mathrm{CD} 11 \mathrm{~b}^{\mathrm{hi}}$ arterial macrophages, respectively, were $\mathrm{GFP}^{+}$and derived entirely from fetal monocytes (Fig. 2g). Fetal monocytes are generated through both FLT-3-dependent and FLT-3-independent pathways ${ }^{10}$. The contribution of fetal liver hematopoiesis to development of the arterial macrophage pool, therefore, is likely underestimated. The data indicate that arterial macrophages are established through differentiation of early as well as late YS-derived EMPs.

In adult mice, E8.5-labeled YS progenitors contributed to the macrophage pool in the aorta to a greater extent than the liver, lung and peritoneum (Fig. 2f,h). Moreover, the appearance of $\mathrm{Td}^{\mathrm{Tomato}} \mathrm{MHCII}^{+}$arterial macrophages in adulthood (Fig. 2i) indicated that $\mathrm{MHCII}^{-}$cells gave rise to $\mathrm{MHCII}^{+}$macrophages sometime after birth, because arterial macrophages in newborn mice were $\mathrm{MHCII}^{-}$(Fig. 2c). The persistence of YS-derived macrophages in the adult aorta was independently verified using $C s f 1 r^{\text {MeriCreMer }} \times R_{R o s}{ }^{\mathrm{mTmG}}$ mice administered TAM at E8.5. These mice express the tamoxifen-inducible MerCreMer fusion protein under control of the macrophage specific mouse $C s f I r$ promoter. YS-derived macrophages appear as $\operatorname{GFP}^{+}(\mathbf{F i g} . \mathbf{2 j})$. The decline in YS labeling of arterial macrophages from $\sim 60 \%$ at birth to $\sim 20 \%$ in adulthood (Fig. 2e,f) could result from replacement of embryonic arterial macrophages by circulating monocytes ${ }^{9,28}$. To address this possibility, pregnant $C X_{3} C R 1^{\text {CreER }}$ mice were injected with TAM at E18.5. The approach labeled most arterial macrophages (and microglia) in $C X_{3} C R I^{\text {creER }}$ $R 26^{\text {Tomato }}$ mice at birth, but few blood monocytes (Fig. 2k, l). Td $^{\text {Tomato }}$ labeling in arterial macrophages, but not microglia, decreased during the first 2 weeks of life (Fig. $2 \mathbf{k}, \mathbf{l})$, suggesting significant turnover and replacement of arterial macrophages with unlabeled circulating monocytes. Consistent with these observations, monocyte influx associated with increased perinatal expression in the aorta of the chemokine CCL2 and the cellular adhesion molecules VCAM-1, E-selectin and ICAM-1 (Fig. 2m, Supplementary Fig. 2b). We investigated the postnatal contribution of definitive hematopoiesis to the adult arterial macrophage pool further using $F l t 3^{\text {cre }}$ x Rosa ${ }^{\mathrm{mT} / \mathrm{mG}}$ reporter mice. Flt $3^{\text {cre }} \times$ Rosa $^{\mathrm{mT} / \mathrm{mG}}$ Ly6C $\mathrm{C}^{\text {hi }}$ blood monocytes were GFP ${ }^{+}$ and derived entirely from HSPC precursors (Fig. 2n). In agreement with our previous 
observations, arterial macrophages in mice comprised both $\mathrm{GFP}^{+}$and $\mathrm{GFP}^{-}$subsets, confirming the dual YS and HSPC origin of these cells (Fig. 2n,o). These observations suggest successive waves of arterial macrophage colonization, initially by an embryonic wave derived from early YS EMP and fetal liver monocytes ${ }^{9-11,24}$ followed by a brief influx of bone marrow-derived monocytes immediately after birth.

\section{$\mathrm{CX}_{3} \mathrm{CL1}-\mathrm{CX}_{3} \mathrm{CR} 1$ interactions determine survival of arterial macrophages.}

Described differences in tissue-specific macrophage requirements for the growth factors macrophage-colony stimulating factor (M-CSF) and granulocyte macrophage-colony stimulating factor (GM-CSF) ${ }^{29,30}$ led us to assess arterial macrophages in $C s f 1^{-/-}$and $C s f 2^{-/-}$mice. We found significantly fewer arterial macrophages in the arteries of $\mathrm{Csfl}^{-/-}$, but not $\mathrm{Csf} 2^{-/-}$mice compared to wild-type mice (Supplementary Figure 3a,b), consistent with other studies demonstrating profound macrophage deficiencies in M-CSF-deficient mice ${ }^{29}$.

While many tissue macrophages lose expression of $\mathrm{CX}_{3} \mathrm{CR} 1$ as they mature ${ }^{13}$, adult mice retain its expression on a large proportion of arterial macrophages (Fig. 3a-c and Supplementary Fig. 3c). Therefore, we investigated whether $\mathrm{CX}_{3} \mathrm{CR} 1$ contributed directly to the maintenance of arterial macrophages. $C X_{3} C R 1^{-/-}$mice had fewer arterial macrophages than wild-type controls as assessed by confocal microscopy (Fig. 3d) and flow cytometry (Fig. 3e). Neutralizing antibodies directed against the $\mathrm{CX}_{3} \mathrm{CR} 1$ ligand $\mathrm{CX}_{3} \mathrm{CL1}$ also decreased arterial macrophage numbers in wild type mice (Fig. 3f). Arterial macrophage proliferation was unchanged in $\mathrm{CX}_{3} \mathrm{CR} 1$-deficient mice compared to wild-type control mice (Fig. 3g), but the percentage of $\mathrm{Fas}^{+}$macrophages (Fig. 3h) and the number of TUNEL ${ }^{+} \mathrm{CD}^{+} 8^{+}$cells (Fig. 3i) was increased in the vessel adventitia, suggesting that $\mathrm{CX}_{3} \mathrm{CR} 1-\mathrm{CX}_{3} \mathrm{CL} 1$ controls the survival of arterial macrophages. We next used $\mathrm{CX}_{3} C L 1^{\text {cherry }}$ mice ${ }^{45}$, which have been modified to replace exon 1 of $C X_{3} C L 1$ with mCherry, to investigate the cellular source of $\mathrm{CX}_{3} \mathrm{CL} 1$. Confocal microscopy analysis of the arterial adventitia in $\mathrm{CX}_{3} C L 1^{\text {cherry }}$ mice showed close proximity of $\mathrm{CX}_{3} \mathrm{CL1}(\mathrm{Cherry})^{+}$cells and $\mathrm{CD} 68^{+}$ resident macrophages (Fig. 3j). Flow cytometry and immunofluorescence staining revealed 2 main populations of $\mathrm{CX}_{3} \mathrm{CL1}^{+}$cells in the aorta of $\mathrm{CX}_{3} C L 1^{\text {cherry }}$ mice, namely $\mathrm{CD} 31^{+}$endothelial cells and PDGFR $\alpha^{+}$mesenchymal cells (Fig. 3k,l). Therefore, arterial macrophage maintenance depends partially on a local $\mathrm{CX}_{3} \mathrm{CR} 1-\mathrm{CX}_{3} \mathrm{CL} 1$ axis. 


\section{Arterial macrophages are maintained independent of monocytes in adulthood.}

To examine the mechanism of arterial macrophage renewal in adult mice, we examined the presence of arterial macrophages in mice deficient for the chemokine receptor CCR2, which have reduced numbers of circulating Ly $6 \mathrm{C}^{\text {hi }}$ monocytes ${ }^{35}$. The arteries of wild-type and $C c r 2^{-/-}$ mice contained comparable numbers of arterial macrophages (Fig. 4a), suggesting that macrophage turnover at steady-state occurs largely independent of circulating monocytes. To assess the rate of macrophage replacement in the arterial tissue, 8-week old C57BL/6J and UBCGFP mice, which express GFP under control of the human ubiquitin C promoter in all tissues, were joined by parabiosis for 8 months. While Ly $6 \mathrm{C}^{\text {hi }}$ and $\mathrm{Ly} 6 \mathrm{C}^{\mathrm{lo}}$ monocyte chimerism in the blood at equilibrium was high ( $\sim 32 \%$ and $\sim 41 \%$, respectively; Fig. 4 b), as expected, macrophage chimerism in the aorta of parabiotic mice was low $(\sim 6 \%)$, suggesting that monocyte contribution to the arterial macrophage pool was limited. Macrophage chimerism was similarly low in the heart, lung and liver of parabiotic mice (Fig. $\mathbf{4 b}$ and $^{12}$ ). As we have shown ${ }^{36}$, macrophage chimerism in the aorta alone in parabiotic mice underestimates the overall contribution of circulating monocytes to the arterial macrophage pool because Ly6C ${ }^{\text {hi }}$ monocyte chimerism in the blood, even at equilibrium, is only $\sim 32 \%$ (Fig. 4b). Assuming that individual $\mathrm{GFP}^{+}$and $\mathrm{C} 57 \mathrm{BL} / 6 \mathrm{~J}$ monocytes can infiltrate the arterial wall equally, for every $\mathrm{C} 57 \mathrm{BL} / 6 \mathrm{~J}$, partner-derived monocyte that entered the aorta of UBC-GFP mice, we also detected two endogenous $\left(\mathrm{GFP}^{+}\right)$ infiltrating monocyte-derived macrophages. Hence, the total contribution of circulating monocytes (UBC-GFP and C57BL/6J) to macrophage accumulation was at most $\sim 17 \%$ (Fig. 4c). Local expansion, which accounts for the remaining $\sim 83 \%$ of $\mathrm{F} 4 / 80^{\mathrm{hi}} \mathrm{CD} 11 \mathrm{~b}^{+}$macrophages, dominated arterial macrophage renewal during steady-state conditions (Fig. 4c). When we parabiotically linked $C c r 2^{-/-}$and UBC-GFP $\left(C c r 2^{+/+}\right)$mice for 5 weeks, monocyte chimerism $\left(\mathrm{GFP}^{+}\right.$cells $)$in the blood $\left(\mathrm{CD} 115^{\mathrm{hi}}\right)$ and aortae $\left(\mathrm{F} 4 / 80^{\mathrm{int}} \mathrm{CD} 11 \mathrm{~b}^{+} \mathrm{Ly}_{6 \mathrm{G}}{ }^{-}\right)$of $\mathrm{CCR} 2^{-/-}$partners was $\sim 82 \%$ and $\sim 73 \%$, respectively (Fig. 4d). Despite high chimerism of partner-derived wild-type monocytes in $\mathrm{Ccr} 2^{-/-}$mice, chimerism of partner-derived $\mathrm{F} 4 / 80^{\mathrm{hi}} \mathrm{CD} 11 \mathrm{~b}^{+}$arterial macrophages in $C \mathrm{cr} 2^{-/-}$mice remained low ( $9 \%$; Fig. 4d). We also independently assessed the monocyte contribution to the arterial macrophage pool by pulse labeling adult $C X_{3} C R 1^{\text {creER }} R 26^{\text {Tomato }}$ mice. Tamoxifen treatment induced $\mathrm{CX}_{3} \mathrm{CR} 1-\mathrm{Td}^{\text {Tomato }}$ expression in $\sim 19 \%$ of blood Ly $6 \mathrm{C}^{\text {hi }}$ monocytes and $\sim 59 \%$ of arterial macrophages (Fig. $4 \mathbf{e})$. Td $^{\text {Tomato }}$ expression remained high $(\sim 50 \%)$ among 
arterial macrophages at 9 and 11 months post labeling (Fig. 4e), but was absent in blood monocytes (Supplementary Fig. 4a and ${ }^{37}$ ), suggesting that maintenance of arterial macrophages depends little on blood monocytes.

Persistence of pulse-labeled $\mathrm{CX}_{3} \mathrm{CR}^{+}$macrophages could also result from slow cell turnover.

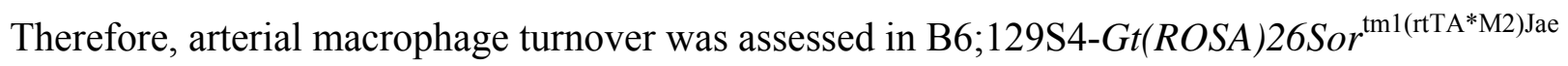
Collal $^{\mathrm{tm} 7(\mathrm{tetO}-\mathrm{HIST} 1 \mathrm{H} 2 \mathrm{BJ} / \mathrm{GFP}) \mathrm{Jae}} / \mathrm{J}(\mathrm{H} 2 \mathrm{~B}-\mathrm{GFP})$ mice, in which doxycycline treatment induces the expression of H2B-GFP ubiquitously ${ }^{38}$. Cellular expression of H2B-GFP was induced in adult mice by doxycycline treatment for 4 weeks and the loss of GFP fluorescence per cell, which is indicative of cell division, was monitored during a 2 month chase period. As expected, H2B-GFP expression in blood monocytes and arterial macrophages exceeded background by orders of magnitude following 4 weeks of doxycycline (Fig. $4 \mathbf{f}$ and Supplementary Fig. 4b). Consistent with observations that myeloid precursors turnover rapidly ${ }^{38}$, expression of H2B-GFP in blood Ly6C ${ }^{\text {hi }}$ monocytes declined below the limit of detection after 2 months (Supplementary Fig. 4b). H2B-GFP expression was also completely lost in some arterial macrophages $(\sim 25 \%)$ or the mean fluorescence intensity (MFI) of the GFP signal was dramatically reduced in others (Fig. 4f), indicating significant turnover of arterial macrophages within 2 months. To estimate further the turnover and loss rate of arterial macrophages, we generated a mathematical model using a 3state absorbing continuous time Markov chain (CTMC). The approach assumed 2 transient states of $\mathrm{GFP}^{+}$macrophages with different rates of GFP loss, and 1 absorbing state representing cells that have lost GFP expression (i.e. GFP ${ }^{-}$macrophages) (see Methods). Fitting the mathematical model to the observed dilution of the H2B-GFP signal in arterial macrophages suggested a turnover rate of $\sim 84 \%$ every 12 months for these cells (Fig. 4g). Independently, 5bromodeoxyuridine (BrdU) injections into wild-type mice every other day for 9 days labeled 25\% of aortic macrophages (Fig. 4h and Supplementary Fig. 4c). Hence, arterial macrophage turnover is dynamic.

\section{Arterial macrophages self renew following exposure to bacteria.}

To address how arterial macrophages are replenished during inflammation we assessed macrophage repopulation in irradiated CD $45.2^{+}$mice transplanted with whole bone marrow from CD45. $1^{+}$mice. Recipient mice displayed near complete donor chimerism among blood 
leukocytes 6 months following transplantation (Fig. 5a). Brain microglia excepted ${ }^{39,40}$, donor chimerism of resident macrophages in the liver, heart, lung and aorta exceeded 70\% (Fig. 5a), consistent with previous reports that lethal radiation impairs the local repopulation capacity of tissue-resident macrophages ${ }^{41}$.

To assess macrophage turnover following infection, mice were either exposed to the Gramnegative bacterial cell wall component, lipopolysaccharide (LPS) or subjected to surgical puncture of the cecum. The number of $\mathrm{F} 4 / 80^{\mathrm{hi}} \mathrm{CD} 11 \mathrm{~b}^{+} \mathrm{CD} 115^{+}$Lyve- $1^{+}$resident arterial macrophages contracted immediately following LPS or cecal puncture (Fig. 5b and Supplementary Fig. 5a ${ }^{42}$. Depletion of resident macrophages associated with accumulation of neutrophils (Supplementary Fig. 5b), Ly6C ${ }^{\text {hi }}$ monocytes (Fig. 5b) and a distinct macrophage population identified as $\mathrm{F} 4 / 80^{\mathrm{hi}} \mathrm{CD} 11 \mathrm{~b}^{++} \mathrm{CD} 115^{-} \mathrm{Lyve}^{-}{ }^{-}$(Fig. 5b,c and Supplementary Fig. 5c). By one week, resident $\mathrm{CD} 115^{+}$Lyve- $1^{+}$macrophage numbers rebounded to levels observed during steady state conditions (Fig. 5b,c,e), while neutrophils, monocytes and CD115 ${ }^{-}$Lyve- $1^{-}$ macrophages were nearly absent (Fig. 5b,c and Supplementary Fig. 5b). Arterial macrophage numbers rebounded in LPS-exposed $\mathrm{Ccr}^{-/-}$mice as well (Fig. 5b), indicating that local expansion rather than monocyte recruitment was the dominant mechanism of recovery. In agreement with this observation, LPS exposure increased the number of aortic macrophages in either $\mathrm{S}, \mathrm{G}_{2}$, or M phases of the cell cycle compared to wild-type mice (Fig. 5f). In addition, we exposed parabiotic mice either to LPS or subjected them to cecal puncture. Partner chimerism was low among arterial resident CD $115^{+}$Lyve- $1^{+}$macrophages, yet chimerism of newly infiltrating $\mathrm{CD} 115^{-}$Lyve- $1^{-}$macrophages was high, suggesting that monocytes were the immediate precursors of these cells (Fig. $\mathbf{5 c}, \mathbf{d})$. Intravenous transfer of $\mathrm{Ly} 6 \mathrm{C}^{\text {hi }}$ monocytes into LPS-treated mice showed that Ly6 $\mathrm{C}^{\text {hi }}$ monocytes gave rise to $\mathrm{CD} 115^{-}$Lyve- $1^{-}$macrophages, but not CD115 $5^{+}$yve- $1^{+}$macrophages in the aorta (Fig. 5g). Moreover, CD115 ${ }^{-}$Lyve- $1^{-}$arterial macrophages displayed an increased in vivo capacity to phagocytose bacteria compared to CD $115^{+}$Lyve- $1^{+}$arterial macrophages (Fig. 5h), indicating that functional differences exist between the two subsets of macrophages.

To determine if YS-derived arterial macrophages respond differently than bone marrow-derived arterial macrophages, adult E8.5-labeled $C X_{3} C R I^{\text {creER }} R 26^{\text {Tomato }}$ mice were either exposed to LPS 
or subjected to cecal puncture and assessed for the proportion of E8.5-labeled vs. unlabeled arterial macrophages during the macrophage recovery phase to determine the preferential expansion of one population over another. Neither LPS administration nor polymicrobial sepsis affected the percentage of $\mathrm{F} 4 / 80^{\mathrm{hi}} \mathrm{CD} 11 \mathrm{~b}^{+}$macrophages that were $\mathrm{Td}$ tomato positive (Fig. $\mathbf{5 i}$ ), suggesting equal self-renewal capabilities of the 2 subsets of arterial macrophages during infection. Microarray analysis of aortic macrophages during homeostasis and after recovery from sepsis revealed bacterial exposure had little effect on the transcriptional program of selfrenewing macrophages (Fig. 5j, Supplementary Fig. 5d). Of 10391 genes analyzed, only 12 were differentially expressed, 10 increased and 2 decreased, in arterial macrophages from mice subjected to cecal puncture compared to steady-state control mice. In addition, in vitro, arterial macrophages could phagocytose bacteria before and after sepsis to the same extent (Supplementary Fig. 5e). Therefore, arterial macrophages return to functional homeostasis rapidly after infection.

\section{Discussion}

Here, we identified the molecular signature of arterial macrophages, their developmental pathways and key mechanisms that ensure their homeostasis. Arterial macrophages, we showed, are distinct among tissue resident macrophages. Multiple fate mapping approaches demonstrated that arterial macrophages originate embryonically from $\mathrm{CX}_{3} \mathrm{CR}^{+}$precursors and postnatally from circulating monocytes immediately after birth. In adulthood, arterial macrophages were maintained by $\mathrm{CX}_{3} \mathrm{CR} 1-\mathrm{CX}_{3} \mathrm{CL} 1$ interactions and local proliferation rather than recruitment of circulating monocytes. Self-renewal also restored arterial macrophages to functional homeostasis after severe depletion induced by polymicrobial sepsis.

The microarray database generated by the Immunological Genome Consortium provides a valuable resource for comparing gene-expression profiles of macrophages from different organs ${ }^{14}$. Consistent with evidence demonstrating diversity among macrophage populations, our gene expression and protein analyses revealed distinct patterns for arterial macrophages relative to other tissue macrophages. The data identified GO enrichment of transcripts with annotated functions that equip arterial macrophages for specialized local functions, supporting the concept 
that meaningful assessment of macrophage function requires careful consideration of the tissue context in which they reside.

Tissue macrophages arise from 2 distinct developmental programs; early YS-derived erythromyeloid progenitors (EMPs) that give rise to macrophages without monocyte intermediates, and fetal monocytes that derive from late c-Myb ${ }^{+}$EMPs generated in the $\mathrm{YS}^{10,11}$. These pathways contribute variously to macrophage development in several tissues including the brain, skin, heart, liver and lung $5,8,13,23,24,43$. Consistent with these findings, $\mathrm{F} 4 / 80^{\text {hi }} \mathrm{CD} 11 \mathrm{~b}^{\mathrm{lo}}$ arterial macrophages and $\mathrm{F} 4 / 80^{\mathrm{lo}} \mathrm{CD} 11 \mathrm{~b}$ hi fetal monocytes were readily identified in aortae of embryonic (E16.5) mice. $C X_{3} C R 1-, C s f 1 r$-, and Flt3-driven fate mapping approaches indicated that arterial macrophages were derived from early YS EMPs as well as fetal monocytes. Our data also indicated that arterial macrophage colonization associates with a period bone marrow-derived monocyte recruitment shortly after birth. Development of the arterial macrophage pool, therefore, is unique. The maintenance of intestinal macrophages also depends on circulating monocytes, but renewal is constant and continues throughout adult life ${ }^{28}$. In arteries, the period of postnatal monocyte influx was brief, corresponding with transient expression of chemokines and cell adhesion molecules implicated in monocyte recruitment. While adult arteries contained sizeable populations of both YS and bone marrow-derived macrophages, the relative contribution of the 2 subsets of macrophages to vessel homeostasis remains unknown.

In many tissues, resident macrophages lose expression of $\mathrm{CX}_{3} \mathrm{CR} 1$ during development ${ }^{13}$. In addition to retaining macrophage expression of the chemokine receptor in adulthood, $\mathrm{CX}_{3} \mathrm{CL} 1$ blockade and examination of $\mathrm{CX}_{3} \mathrm{CR}^{-/-}$mice indicated that $\mathrm{CX}_{3} \mathrm{CR} 1-\mathrm{CX}_{3} \mathrm{CL} 1$ interactions determine the survival of arterial macrophages, possibly through Fas-Fas ligand interactions. $\mathrm{CX}_{3} \mathrm{CR} 1-\mathrm{CX}_{3} \mathrm{CL} 1$ similarly promotes survival of macrophages in the brain ${ }^{31}$, kidney ${ }^{32}$, solid tumors ${ }^{34}$ and circulating Ly6 $\mathrm{C}^{\text {lo }}$ blood monocytes ${ }^{33}$. Visualization of the arterial macrophage niche using $\mathrm{CX}_{3} C L 1^{\text {cherry }}$ reporter mice further showed that $\mathrm{CD} 31^{+}$endothelial cells and $\mathrm{PDGFRa}^{+}$mesenchymal cells produced $\mathrm{CX}_{3} \mathrm{CL} 1$ locally in the artery. The relative contribution of these $\mathrm{CX}_{3} \mathrm{CL} 1$ producers to macrophage survival, however, is not known. The data also suggested the dependence of macrophage survival in the arterial wall on signaling pathways other than $\mathrm{CX}_{3} \mathrm{CR} 1$, because not all arterial macrophages express the receptor, and $\mathrm{CX}_{3} C R 1^{-/}$ 
mice still contain a moderate population of aortic macrophages. M-CSF deficiency similarly associated with fewer arterial macrophages, although it remains to be determined if M-CSF regulates macrophage differentiation, survival, and/or proliferation.

Mathematical modeling of loss of arterial macrophages in H2B-GFP mice predicted near complete replacement of the macrophage population within $\sim 1$ year. Arterial macrophage turnover, therefore, is dynamic. Analysis of parabionts, $C C R 2^{-/-}$mice and pulse-labeled adult $\mathrm{CX}_{3} C R 1^{\text {creER }} \mathrm{R} 26^{\text {Tomato }}$ mice indicated that local proliferation rather than monocyte recruitment drives arterial macrophage renewal in the steady state and during polymicrobial sepsis. This result contrasts with a report on macrophage maintenance in the heart, where bone marrowderived cells progressively replaced macrophages with age 9 . The data further showed that the arterial macrophage response to bacteria is many-sided. Infection led first to the recruitment of Ly6C ${ }^{\text {hi }}$ monocytes and their differentiation into CD $115^{-}$Lyve- $1^{-}$macrophages that functioned to phagocytose bacteria. This was followed by the self-renewal and re-establishment of functional homeostasis of CD $115^{+}$Lyve- $1^{+}$resident macrophages. The diversity of origins (successive contributions of YS, fetal liver and conventional hematopoiesis) of arterial macrophages highlights the importance of tissue-specific extrinsic factors, including $\mathrm{CX}_{3} \mathrm{CR} 1-\mathrm{CX}{ }_{3} \mathrm{CL} 1$ interactions, in maintaining their abundance. Of note, macrophage proliferation also amplifies arterial pathology, as we have previously observed in atherosclerosis ${ }^{36}$. Therefore, future design of therapeutic strategies that target arterial macrophages will require not only elucidation of the mechanisms that maintain them, but their activities in specific disease contexts. 


\section{Author Contributions}

S.E. and A.L. conceived the project, designed and performed experiments, and analyzed and interpreted data. R.B., N.D., J.C., M.R., M.E.M., J.W., E.S., C.L., B.L., L.R., T.J.Y., J.S.L., P.W., I.H., S.E., and R.K., performed experiments and helped interpret the data. M.O., J.B., C.C.J.Z., M.v.L-C., C.M.T.B., P.L, M.H., F.K.S, C.C., M.P., I.H., G.J.R., S.E., A.O.G., M.C., and B.B.R. provided materials, intellectual input and edited the manuscript. C.S.R. conceived the project, designed and performed experiments, supervised the study, and wrote the manuscript.

\section{Microarray Data Accession Numbers}

Principal component analysis was performed to compare naive arterial macrophage microarray

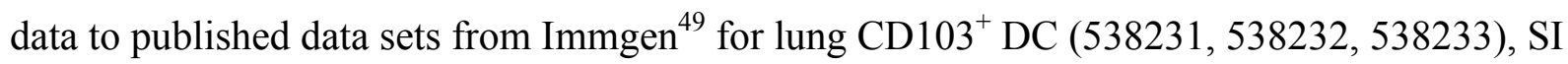
CD $103^{+} \mathrm{DC}(854251,854252,854253), \mathrm{MLN}_{\mathrm{CD}}{ }^{+} \mathrm{DC}(538242,538243,538244), \mathrm{MLN}$ $\mathrm{CD}^{+} \mathrm{DC}(538252,538253,538254)$, lung alveolar MF $(538282,538283,538284), \mathrm{SI}_{\mathrm{CD} 11 \mathrm{~b}^{+}}$ MF (854262, 854263, 854264), microglia (854326, 854327, 854328), and RP MF (605853, $605854,605855)$.

\section{Acknowledgements}

We would like to acknowledge the administrative assistance of B. Bali. This work was supported by a CIHR New Investigator Award (MSH136670), a CIHR operating grant (MOP133390), an Ontario Lung Association/Pfizer Award, and the Peter Munk Chair in Aortic Disease Research (C.S.R). S.E. was supported by an Ontario Graduate Scholarship. J.W.W. was supported by an NIH postdoctoral training grant (NIH 5T32 DK007296). The authors declare no conflicts of interest.

\section{Competing Financial Interests}

The authors declare no competing financial interests. 


\section{Online Methods}

\section{Animals}

C57BL/6J (WT), B6.Cg-Tg(Itgax-Venus)1Mnz/J (CD11c-eYFP), B6.129P2(Cg)-

$C x 3 c r 1^{\text {tm2.1(cre/ERT)Litt } / W g a n J}\left(\mathrm{CX}_{3} \mathrm{CR} 1^{\mathrm{CreER}}\right), 129 \mathrm{~S}-Z b t b 46^{\text {tmlKmm} / \mathrm{J}}\left(\mathrm{Zbtb}^{\mathrm{C}} 6^{\text {GFP/+}}\right), \mathrm{B} 6.129 \mathrm{P} 2(\mathrm{C})-$

Cx3crl $1^{\text {tm2.1(cre/ERT2)Jung } / \mathrm{J}}\left(\mathrm{CX}_{3} \mathrm{CR} 1^{\mathrm{CreER}}\right), \mathrm{B} 6.129 \mathrm{P}-\mathrm{Cx} 3 \mathrm{cr} 1^{\text {tmlLitt } / \mathrm{J}}\left(\mathrm{CX}_{3} \mathrm{CR} 1^{\mathrm{gfp} /{ }^{+}}\right), \mathrm{B} 6 . \mathrm{Cg}-$

$\operatorname{Tg}(\mathrm{Cx} 3 \mathrm{cl1} / \mathrm{mCherry}) 1 \mathrm{Jung} / \mathrm{J}\left(\mathrm{CX}_{3} \mathrm{CL}^{\text {cherry }}\right), \mathrm{B} 6.129 \mathrm{~S} 4-\mathrm{Ccr} 2^{\text {tmllfc }} / \mathrm{J}\left(\mathrm{CCR} 2^{-/-}\right), \mathrm{B} 6 ; \mathrm{C} 3 \mathrm{Fe} a / a-$

Csfl ${ }^{\text {op }} / \mathrm{J}\left({\left.\mathrm{M}-\mathrm{CSF}^{-/}\right)}\right)$B6;129S4-Gt(ROSA)26Sor ${ }^{\text {tml(rtTA*M2)Jae }}$ Collal $^{\text {tm7(tetO-HIST1H2BJ/GFP)Jae } / \mathrm{J}}$

(H2B-GFP), and B6.SJL-Ptprc ${ }^{\mathrm{a} P e p} 3$ b/BoyJ (CD45.1), C57BL/6-Tg(UBC-GFP)30Scha/J mice were all purchased from Jackson Laboratories. B6.129-Cx3 $\mathrm{cr} 1 \mathrm{tm} 1 \mathrm{Zm}\left(\mathrm{Cx}_{3} \mathrm{cr}^{-1}\right)$,

C57BL/6NTac were purchased from Taconic. Flt3-Cre and Csfrl-Mer-iCre-Mer mice, which were crossed with Rosa mTmG C57BL6/J reporter mice, were kindly provided by Dr. Slava Epelman and Dr. Gwendalyn Randolph. Dr. Filip Swirski provided $C s f 2 r b^{-/}\left(\mathrm{GM}^{-\mathrm{CSFR}^{-/}}\right)$ mice. Studies were carried out using both male and female mice. All animal protocols were approved by the Animal Resource Centre, University Health Network (AUP\# 2902), Toronto, ON.

\section{Animal models and in vivo interventions}

Fate-mapping approaches: $\mathrm{CX}_{3} \mathrm{CR} 1^{\mathrm{CreER}}$ females were bred with $\mathrm{R} 26^{\text {tdTomato }}$ males to generate heterozygous $\mathrm{CX}_{3} \mathrm{CR} 1^{\mathrm{CreER}} ; \mathrm{R} 26^{\text {tdTomato }}$ offspring. To label yolk sac-derived cells, tamoxifen was administered to pregnant females at E8.5 via intra-peritoneal (i.p.) injection at a concentration of $75 \mu \mathrm{g} / \mathrm{g}$ body weight. At E19.5-20.5, pregnant mothers were c-sectioned and pups fostered. The same pup fostering protocol was applied to E18.5 labeling.

Tamoxifen preparation: $100 \mathrm{mg}$ of tamoxifen-free base (Sigma-Aldrich T5648) was added to 0.5 $\mathrm{mL} \mathrm{95 \%} \mathrm{ethanol.} 9.5 \mathrm{~mL}$ corn oil was then added to the mixture and vortexed until dissolved.

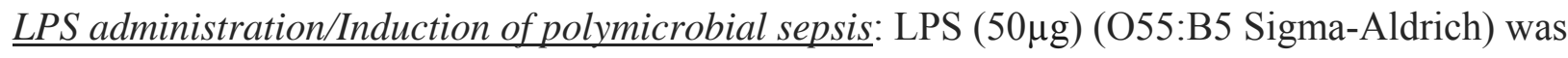
administered by intra-peritoneal injection. A rodent model of sepsis was induced by opening the peritoneal cavity during isoflurane anesthesia. The distal end of the cecum was then perforated using a $23 \mathrm{G}$ needle, and a small drop of feces was extruded through the puncture. The cecum was relocated into the peritoneal cavity, and the peritoneum was closed. Animals were resuscitated by subcutaneous injection of $1 \mathrm{~mL}$ of saline.

H2B-GFP induction: H2B-GFP expression was induced in B6; 129S4-Gt(ROSA) 


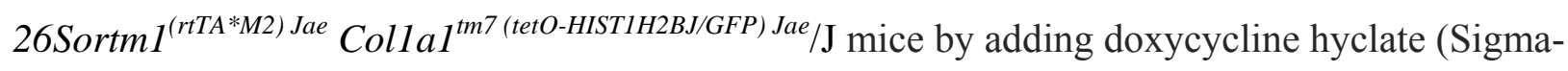
Aldrich) (dissolved at a concentration of $2 \mathrm{mg} / \mathrm{mL}$ in autoclaved water and $1 \% \mathrm{w} / \mathrm{vol}$ of sucrose) to the water supply for 4 weeks.

BrdU incorporation studies: $1 \mathrm{mg}$ BrdU (FITC BrdU Flow Kit; BD Pharmingen) was injected i.p. every other day for 9 days.

Monocyte depletion: Mice were injected i.v. on 5 consecutive days with $200 \mu$ of either PBS (control)- or clodronate-loaded liposomes $(5 \mathrm{mg} / \mathrm{ml}$ ) (clodronateliposomes.com).

Parabiosis: Briefly, after shaving the corresponding lateral aspects of each mouse, matching skin incisions were made from behind the ear to the tail of each mouse, and the subcutaneous fascia was bluntly dissected to create about $1 / 2 \mathrm{~cm}$ of free skin. The olecranon and knee joints were attached by a mono-nylon 5.0 (Ethicon, Albuquerque, NM), and the dorsal and ventral skins were approximated by continuous suture. Percent chimerism was defined as $\% \mathrm{GFP}^{+} /\left(\% \mathrm{GFP}^{+}+\right.$ $\left.\% \mathrm{GFP}^{-}\right)$in $\mathrm{GFP}^{-}$mice, and as $\% \mathrm{GFP}^{-} /\left(\% \mathrm{GFP}^{-}+\% \mathrm{GFP}^{+}\right)$in $\mathrm{GFP}^{+}$mice.

Bone Marrow Transplantation: Naïve wild type mice (CD45.2 $\left.{ }^{+}\right)$were lethally irradiated (10 Gy). 4-7 hours after irradiation, animals were reconstituted with CD45.1 $1^{+}$total bone marrow cells from B6.SJL-Ptprc ${ }^{\mathrm{a}} \mathrm{Pep} 3^{\mathrm{b}} / \mathrm{BoyJ}$ mice. A total of $3 \times 10^{6}$ cells were injected intravenously. Animals were allowed to recover for a minimum of 10 weeks.

Phagocytosis: Aortic macrophages were harvested from C57/B6J wild-type animals before and 7-day following induction of sepsis by cecal puncture and incubated with $\mathrm{pHrodo}^{\mathrm{TM}}$ E. coli BioParticles $^{\circledR}$ (Life Technologies) according to the manufacturer's protocol. Phagocytic activity was determined by flow cytometry. For in vivo phagocytosis assays, C57/B6 adult mice were injected with LPS (50 ug) and 8 hours later injected intravenously with of $200 \mathrm{uL}$ of pHrodo ${ }^{\mathrm{TM}}$ E. coli BioParticles ${ }^{\circledR}$ at a concentration of $2 \mathrm{mg} / \mathrm{mL}$. Aortic macrophages were harvested 4 hours post injection of $E$. coli particles (12 hours after LPS). Phagocytic activity was determined by flow cytometry.

$\underline{C X}_{3}$ CL1 Blockade: C57/B6 adult mice were implanted with osmotic pumps (Alzet 200 microlitre micro-osmotic pumps) containing either $\mathrm{CX}_{3} \mathrm{CL} 1$ neutralizing antibody (R\&D MAB571) or ratIgG2 $2_{\mathrm{a}}$ isotype control antibody ( $\left.\mathrm{R} \& \mathrm{D} \mathrm{MAB} 006\right)$ for 10 days.

$\underline{\text { Ly6C }} \mathrm{C}^{\text {high }}$ monocyte adoptive transfer: Bone marrow cells were collected from the spines, hips, femurs, tibias and fibulas of adult C57BL/6-Tg (UBC-GFP) ${ }^{30 \text { Scha/J }}$ mice. Magnetic-activated cell sorting was used to sort on $\mathrm{CD} 115^{+}$cells. Ly6 $\mathrm{C}^{\text {high }}$ monocytes were subsequently flow-sorted on 
CD115 Ly6C ${ }^{\text {high }}$. Immediately after LPS injection, 3 million Ly6 ${ }^{\text {high }} \mathrm{CD} 115^{+} \mathrm{GFP}^{+}$monocytes were injected intravenously. Aortae were collected from transplant recipients at time points after LPS exposure as indicated in figures.

\section{Cells.}

Isolation and ex vivo methods: Peripheral blood for flow cytometric analysis was collected by cardiac puncture using a $50 \mathrm{mM}$ EDTA solution as anticoagulant. Erythrocytes were lysed using RBC Lysis Buffer (BioLegend). The total white blood cell count was determined by preparing a 1:20 dilution of (undiluted) peripheral blood obtained from the orbital sinus using heparin-coated capillary tubes in RBC Lysis Buffer (BioLegend). After organ harvest, single-cell suspensions were obtained as follows: for bone marrow, the femur of one leg was crushed with mortar and pestle and homogenized through a 40- $\mu \mathrm{m}$-nylon mesh. Spleens were homogenized through a 40$\mu \mathrm{m}$-nylon mesh, after which RBC lysis was performed using RBC Lysis Buffer (BioLegend). For aortic tissue, the aorta was perfused with $10 \mathrm{ml}$ PBS before digestion. The entire aorta (from the aortic sinus to the iliac bifurcation) was cut in small pieces and subjected to enzymatic digestion with $450 \mathrm{U} \mathrm{ml}^{-1}$ collagenase I, $125 \mathrm{U} \mathrm{ml}^{-1}$ collagenase XI, $60 \mathrm{U} \mathrm{ml}^{-1}$ DNase I and 60 $\mathrm{U} \mathrm{ml}^{-1}$ hyaluronidase (Sigma-Aldrich) for 10 to 40 minutes (depending on age) at $37^{\circ} \mathrm{C}$ while shaking. Liver, lung, heart, femoral and carotid arteries were also processed in the same manner and digested for 30 minutes. Single-cell suspensions of digested tissues were obtained by homogenizing digested tissue though $40-\mu \mathrm{m}$-nylon mesh. Single-cell suspensions of brain tissue were obtained by direct homogenization through a $40-\mu \mathrm{m}$-nylon mesh.

\section{Confocal Microscopy.}

En face immune-staining was performed as described previously $(1,2)$. Mice were perfused with PBS followed by $2 \%$ paraformaldehyde (PFA), and the ascending aorta was dissected. Aortas were permeabilized with $0.2 \%$ Triton X-100 and $0.1 \mathrm{M}$ Glycine for 10 minutes at room temperature, and endogenous peroxidase activity was by quenched by incubating with $3 \% \mathrm{H}_{2} \mathrm{O}_{2}$ was for 45 minutes. Biotin-conjugated anti-mouse CD68 (Abd Serotec) and was incubated overnight at $4^{\circ} \mathrm{C}$. Samples were then incubated with Streptavidin HRP for 30 minutes, followed by FITC-conjugated Tyramide for 10 minutes (Perkin Elmer). To visualize $\mathrm{CX}_{3} \mathrm{CL} 1$, rabbit antimCherry (1:200; Novus Biologicals, NBP-2-25157) was incubated overnight followed by 
staining with goat anti-rabbit Alexa Flour 568 (1:400; ThermoFisher Scientific, A-11046)

secondary antibodies for 2 hours at room temperature on select samples. Nuclei

were counterstained with Hoechst 33342 (Molecular Probes). For TUNEL staining, aortae were incubated with TUNEL reaction mixture (TMR red In situ Cell Death Detection Kit, Roche Applied Science) for $1 \mathrm{~h}$ at $37^{\circ} \mathrm{C}$. The arch was opened and mounted on glass slides with the intima facing the cover slip. En face images were obtained using a confocal microscope equipped with 40X and 60X oil objectives (FluoView-1000; Olympus). For FLT3-cre x Rosa$\mathrm{mTmG}$ and Csfrl-Mer-iCre-Mer x Rosa-mTmG lineage tagging studies, aortas were fixed in 4\% PFA and 30\% sucrose, then blocked with $0.2 \%$ BSA, 0.1\% Triton X-100, and 5\% donkey serum in PBS and immune-stained with rat anti-mouse CD68 (Bio-Rad MCA1957). Samples were then stained with Cy5-conjugated secondary antibody (Jackson ImmunoResearch) raised in donkey against ratIgG and imaged using a Leica SPE confocal microscope.

For immunofluorescence on aortic cross-sections, tissues were fixed in 4\% PFA, rinsed with PBS, then cryoprotected with 20\% sucrose in PBS and frozen in OCT. $5 \mu \mathrm{m}$ transverse cryosections were dried at room temperature for 10 minutes, fixed for 15 minutes in $2 \%$ PFA, rinsed 3 times in 1x PBS, then blocked for 1 hour in 2\% normal goat serum in PBS. Sections were then incubated with either rat anti-CD31 (1:200; Novus Biologicals, NB600-1475) or rat anti-CD140a (1:200; BD Biosciences, 558774) and rabbit anti-mCherry overnight. Sections were then rinsed 3 times in 1x PBS, then incubated goat anti-rat Alexa Flour 647 (1:400; ThermoFisher Scientific, A-21247) and goat anti-rabbit Alexa Flour 568 secondary antibodies for 2 hours at room temperature, protected from light. Nuclei were counterstained with $10 \mu \mathrm{g} / \mathrm{ml}$ Hoechst 33258 in $\mathrm{ddH}_{2} \mathrm{O}$ for 10 minutes before slides were mounted with 50:50 glycerol:PBS and stored at $-20 \mathrm{C}^{\circ}$ until imaging. Images were captured on an Zeiss Observer V spinning disk confocal microscope.

\section{RNA Microarray.}

Aortic macrophages $\left(\mathrm{CD} 11 \mathrm{~b}^{\text {high }} \mathrm{F} 4 / 80^{\text {high }} \mathrm{CD} 45^{+} \mathrm{MerTK}^{+} \mathrm{CD} 64^{+}\right)$were isolated from C57/B6 wildtype male mice aged 6-8 weeks before and 7 days after induction of sepsis by cecal puncture. 1820 aortas were pooled per sample. Sorting was conducted on the MoFlo Astrios BRVY. Arterial macrophage purity was $>99 \%$ (Supplementary Fig. 5). RNA was extracted using the PicoPure RNA Isolation Kit (Life Technologies). The total concentration and quality of RNA was 
determined using an Agilent 2100 Bioanalyzer (Agilent Technologies) according to the manufacturer's instructions. RNA transcripts were amplified using the Nugen ovation Pico WTA V2 kit. 3ng of total RNA was amplified according the manufacturer's protocol. The amplification of RNA included amplification at the 3' end as well random amplification throughout the transcript using Ribo-SPIA technology. 5ug of cDNA was used to generate STcDNA using the WT-Ovation Exon Module and 5ug of ST-cDNA was fragmented and labeled with Encore Biotin Module. RNA was hybridized on the Affymetrix Mouse Gene 1.0 ST array. Arrays were hybridized at $45^{\circ} \mathrm{C}$ for $16-18$ hours, washed with Affymetrix fluidic station p450 and scanned with Affymetrix 7G scanner. Affymetrix gene expression console was for QC and to generate QC reports.

Probe set expression levels were calculated using the multi-array procedure (RMA), which is available within the oligo Bioconductor package for the R statistical software project where raw intensity values were background corrected and normalized (3). Probe sets with no gene assignments and/or raw intensities $<120$ were filtered out. In cases where multiple probe sets mapped onto a single gene, the probe set with the highest intensity was selected for further analysis. Principal component analysis was performed to compare naive arterial macrophage microarray data to published data sets from Immgen (4) for lung CD103 ${ }^{+}$DC $(538231,538232$, 538233), SI CD103 ${ }^{+} \mathrm{DC}(854251,854252,854253)$, MLN CD4 ${ }^{+} \mathrm{DC}(538242,538243,538244)$, MLN CD8 ${ }^{+}$DC (538252, 538253, 538254), lung alveolar MF (538282, 538283, 538284), SI $\mathrm{CD}_{11 b^{+}} \mathrm{MF}(854262,854263,854264)$, microglia $(854326,854327,854328)$, and RP MF $(605853,605854,605855)$ using the prcomp command in R. RMA-adjusted values were then compared using a student`s t-test with significance set $\mathrm{p}<0.05$.

\section{qRT-PCR}

RNA was extracted from whole aorta using a TRIzoß (Life Technologies) according to manufacturer protocol. RNA concentration was obtained using a Nanodrop ND100 spectrophotometer. cDNA was synthesized using qScript cDNA SuperMix (Quanta BioSciences) according to manufacturer protocol. Transcripts were then detected using specific primers (see Supplementary Table 5) using SYBR Green Master (Roche) detected on a 
LightCycler 480 (Roche). Hprt was used as the housekeeping gene; values were compared using the $2^{-\Delta \Delta \mathrm{Ct}}$ method. Samples were run in triplicate and averaged.

\section{Mathematical modeling.}

MФ turnover was predicted in mice with ubiquitous, doxycycline-inducible expression of an H2B-GFP fusion protein using a Continuous Time Markov Chain (CTMC). The system was modeled as a 3-state absorbing CTMC, two transient states representing the two $\mathrm{GFP}^{+}$ populations of macrophages having different rates of GFP loss and one absorbing state representing the cells that lost the GFP signal (i.e. became GFP negative) (Supplementary Table 2). This system generates a matrix of differential equations and each equation represents the transition probability rate equation of one cell moving between any two states. This matrix is the product of two other matrices, the probability matrix P, which contains the Probability density function for the transitions between any two states, and the matrix of rates $Q$, which contains the values of the probability rates. Assuming Initial conditions of [ 0.70 .30$]$; the form of the Markov Chain shows a representation of unconditional probabilities of reaching each state, and has the following form:

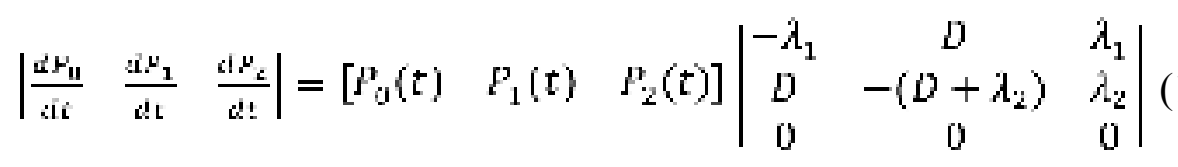

From (1), a total of three simultaneous differential equations can be derived through matrix multiplication. Solving the three differential equations simultaneously gives the following three equations:

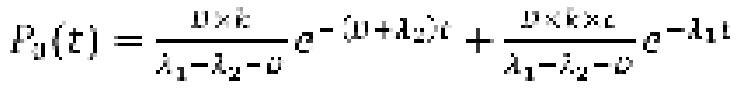

$$
\begin{aligned}
& P_{1}(t)=k e^{-\left(u+\lambda_{2}\right) t}(3)
\end{aligned}
$$

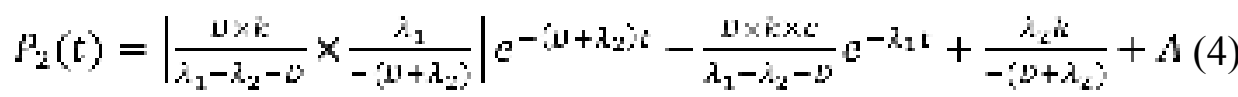

Where $k, c, A$ are arbitrary constants of integrations.

Next, the integration constants were determined using the Initial Conditions stated previously. For the purpose of the modeling and because of the properties of the Markov chains, only the $k$ 
and $c$ were determined as $A$ can be easily calculated using the normality property of the Markov chains. Determination of the values of constants and substituting with them gives the equations for the probability (i.e. proportion) of each cell population, in this case two macrophage populations, being GFP+ at any given time point:

$$
\begin{gathered}
P_{J}(t)=\frac{3}{10}\left|\frac{1}{\lambda_{1}-\lambda_{2}-\nu}\right| e^{-\left\{\nu+\lambda_{2}\right\rangle t}+\left[\left(\frac{3}{10} \times \frac{\lambda_{1}-\lambda_{c}}{\lambda_{1}-\lambda_{2}-\nu}\right)-\frac{D}{\lambda_{1}-\lambda_{2}-\nu}\right] e^{-\lambda_{1} t} \\
P_{1}(t)=\frac{3}{10} e^{-\left(\nu-\lambda_{2}\right\rangle c}(6)
\end{gathered}
$$

Adding equations (5) and (6) gives the general equation for the percent GFP+ cells at any time point:

$$
P_{C Y P^{+}}(t)=X C^{-\left(\nu-\lambda_{2} ; i\right.}\left[\frac{D}{\lambda_{1}-\lambda_{2}-v}+1\right]+Y C^{-\lambda_{1} t}\left[\frac{\lambda_{1}-\lambda_{2}}{\left.\lambda_{1}-\lambda_{2}-1\right)}-\frac{\ddot{v}}{Y\left(\lambda_{1}-\lambda_{C}-D\right)}\right]
$$

Where $\mathrm{X}=3 / 10$ and $\mathrm{Y}=7 / 10$.

$\mathrm{X}$ and $\mathrm{Y}$ represent the values that change with the initial conditions of the system. All other parameters are independent of the initial conditions. This equation was then plugged into the non-linear regression fitting code of Mathematica. The fitting was done on the data shown in Supplementary Table 2. Each row was treated as a separate experiment and was fitted separately to increase the accuracy of the model. The average of each of the coefficients from all four fittings was taken and plugged into the original equation. In the case of the proportions being $3 / 10$ and $7 / 10$, the simplified equation becomes the following;

$$
P_{6 y p^{+}}(t)=-77.4923 e^{-0.15229 i}+179.9833 e^{-11.13187 i}
$$

Where $\lambda_{I}=0.15187 / \mathrm{month}, \lambda_{2}=0.043141 / \mathrm{month}$, and $D=0.10915 / \mathrm{month}$.

All values were generated to a precision level up to the $13^{\text {th }}$ decimal place, but for simplicity, we are only showing up to the $4^{\text {th }}$ decimal place. The fitting was successful for the MFI data as well with changed coefficients, therefore fulfilling the conditions placed on the model previously (Data not shown).

The resulting fit in equation (8) (Hence forth referred to as Average fit) was plotted on Matlab; an extra constant term was added to the model to correct for any changes in the starting 
point from 100. This was done for normalization purposes to match the normalization condition in the DOX on procedure and the changes made by the term were on the order of $0.1-1$, hence it was not significant to the values of the model. The values were imported into the curve-fitting tool Matlab. The tool compares the function to the values generated and generates an $\mathrm{R}^{2}$-value and then plots the data points to validate the model and calculates the validation Sum of the Square of Errors (SSE) and the Root Mean Square Error (RMSE) (which is the same as the standard deviation), both of which should be minimized (Supplementary Tables 2, 3). The curve fitting tool was run on the four fittings along with their respective datasets (Supplementary Table 3 ) and the Average fit function was run four times, each time using a different data set (one of the four experiments) (Supplementary table 3). The $\mathrm{R}^{2}$-values for all runs was 1.0, which confirms that the model is working and the SSE and RMSE values for each run are shown in Supplementary Table 3 and Supplementary Table 4. The RMSE on average was 5.75, which is acceptable as a difference of $+/-5$ is not significant on the range of the dependent variable in this case, which is from 0-100. The Average fit was then plotted with the corresponding error bars for each calculated data point as well as the data point in the same plot for visual confirmation that the points lie within the prediction limits of the model. To confirm that our model predictions and strength are independent of the initial conditions used in the calculations; equation (7) was imported into Matlab with the average values of the coefficients substituted and the values marked in yellow were changed in accordance with 0.1 steps. The functions produced from all steps were plotted on the same plot along with the Average fit. All the plots were identical and there was a small difference between them and the Average fit which is owing to the difference in the significance and number of decimal places generated during the simplification process. The difference is not significant, however (Data not shown).

\section{Flow cytometry.}

Antibodies to the following were used for flow cytometric analyses are provided in

Supplementary Table 5. Data was acquired on an LSRII flow cytometer (BD Biosciences) and analyzed with FlowJo v8.8.6 (Tree Star, Inc.). Aorta, heart, liver, lung, and brain tissue were treated with FcBlock (BD Biosciences) for 15 minutes prior to incubation with antibody cocktail for an additional 30 minutes. Samples were fixed prior to flow analysis (BD Cytofix). Cell-cycle analysis was carried out using FxCycle violet stain (Invitrogen) on 95\% ethanol fixed samples. 


\section{Statistics.}

Results are expressed as either mean \pm SEM or mean \pm SD. The statistical tests used included unpaired Student's $t$ test using Welch's correction for unequal variances and one-way analysis of variance followed by Tukey's or Newman-Keuls multiple comparison test. $P \leq 0.05$ was considered to denote significance. 


\section{References}

1. Akazaki, K. A concept of reticuloendothelial system. Tohoku J Exp Med 76, 107-118 (1962).

2. Naito, M., Yamamura, F., Nishikawa, S. \& Takahashi, K. Development, differentiation, and maturation of fetal mouse yolk sac macrophages in cultures. J Leukoc Biol 46, 1-10 (1989).

3. van Furth, R. \& Cohn, Z. A. The origin and kinetics of mononuclear phagocytes. J Exp Med 128, 415-435 (1968).

4. Samokhvalov, I. M., Samokhvalova, N. I. \& Nishikawa, S. Cell tracing shows the contribution of the yolk sac to adult haematopoiesis. Nature 446, 1056-1061 (2007).

5. Ginhoux, F. et al. Fate mapping analysis reveals that adult microglia derive from primitive macrophages. Science 330, 841-845 (2010).

6. Schulz, C. et al. A lineage of myeloid cells independent of Myb and hematopoietic stem cells. Science 336, 86-90 (2012).

7. Hoeffel, G. et al. Adult Langerhans cells derive predominantly from embryonic fetal liver monocytes with a minor contribution of yolk sac-derived macrophages. J Exp Med 209, 1167-1181 (2012).

8. Epelman, S. et al. Embryonic and adult-derived resident cardiac macrophages are maintained through distinct mechanisms at steady state and during inflammation. Immunity 40, 91-104 (2014).

9. Molawi, K. et al. Progressive replacement of embryo-derived cardiac macrophages with age. J Exp Med 211, 2151-2158 (2014).

10. Hoeffel, G. et al. C-myb(+) erythro-myeloid progenitor-derived fetal monocytes give rise to adult tissue-resident macrophages. Immunity 42, 665-678 (2015).

11. Gomez Perdiguero, E. et al. Tissue-resident macrophages originate from yolk-sac-derived erythro-myeloid progenitors. Nature 518, 547-551 (2015).

12. Hashimoto, D. et al. Tissue-resident macrophages self-maintain locally throughout adult life with minimal contribution from circulating monocytes. Immunity 38, 792-804 (2013).

13. Yona, S. et al. Fate mapping reveals origins and dynamics of monocytes and tissue macrophages under homeostasis. Immunity 38, 79-91 (2013). 
14. Gautier, E. L. et al. Gene-expression profiles and transcriptional regulatory pathways that underlie the identity and diversity of mouse tissue macrophages. Nat Immunol 13, 1118 1128 (2012).

15. Majesky, M. W., Dong, X. R., Hoglund, V., Mahoney, W. M. J. \& Daum, G. The adventitia: a dynamic interface containing resident progenitor cells. Arterioscler Thromb Vasc Biol 31, 1530-1539 (2011).

16. Jakubzick, C. et al. Minimal differentiation of classical monocytes as they survey steadystate tissues and transport antigen to lymph nodes. Immunity 39, 599-610 (2013).

17. Meredith, M. M. et al. Expression of the zinc finger transcription factor zDC (Zbtb46, Btbd4) defines the classical dendritic cell lineage. J Exp Med 209, 1153-1165 (2012).

18. Satpathy, A. T. et al. Zbtb46 expression distinguishes classical dendritic cells and their committed progenitors from other immune lineages. J Exp Med 209, 1135-1152 (2012).

19. McGovern, N. et al. Human dermal CD14(+) cells are a transient population of monocytederived macrophages. Immunity 41, 465-477 (2014).

20. Galkina, E. et al. Lymphocyte recruitment into the aortic wall before and during development of atherosclerosis is partially L-selectin dependent. J Exp Med 203, 12731282 (2006).

21. Choi, J. H. et al. Identification of antigen-presenting dendritic cells in mouse aorta and cardiac valves. J Exp Med 206, 497-505 (2009).

22. Choi, J. H. et al. Flt3 signaling-dependent dendritic cells protect against atherosclerosis. Immunity 35, 819-831 (2011).

23. Kierdorf, K. et al. Microglia emerge from erythromyeloid precursors via Pu.1- and Irf8dependent pathways. Nat Neurosci 16, 273-280 (2013).

24. Guilliams, M. et al. Alveolar macrophages develop from fetal monocytes that differentiate into long-lived cells in the first week of life via GM-CSF. J Exp Med 210, 1977-1992 (2013).

25. Medvinsky, A. \& Dzierzak, E. Definitive hematopoiesis is autonomously initiated by the AGM region. Cell 86, 897-906 (1996).

26. Parkhurst, C. N. et al. Microglia promote learning-dependent synapse formation through brain-derived neurotrophic factor. Cell 155, 1596-1609 (2013). 
27. Prinz, M. \& Priller, J. Microglia and brain macrophages in the molecular age: from origin to neuropsychiatric disease. Nat Rev Neurosci 15, 300-312 (2014).

28. Bain, C. C. et al. Constant replenishment from circulating monocytes maintains the macrophage pool in the intestine of adult mice. Nat Immunol 15, 929-937 (2014).

29. Davies, L. C., Jenkins, S. J., Allen, J. E. \& Taylor, P. R. Tissue-resident macrophages. Nat Immunol 14, 986-995 (2013).

30. Ginhoux, F. \& Jung, S. Monocytes and macrophages: developmental pathways and tissue homeostasis. Nat Rev Immunol 14, 392-404 (2014).

31. Boehme, S. A., Lio, F. M., Maciejewski-Lenoir, D., Bacon, K. B. \& Conlon, P. J. The chemokine fractalkine inhibits Fas-mediated cell death of brain microglia. J Immunol 165, 397-403 (2000).

32. Lionakis, M. S. et al. CX3CR1-dependent renal macrophage survival promotes Candida control and host survival. J Clin Invest 123, 5035-5051 (2013).

33. Landsman, L. et al. CX3CR1 is required for monocyte homeostasis and atherogenesis by promoting cell survival. Blood 113, 963-972 (2009).

34. Zheng, J. et al. Chemokine receptor CX3CR1 contributes to macrophage survival in tumor metastasis. Mol Cancer 12, 141 (2013).

35. Serbina, N. V. \& Pamer, E. G. Monocyte emigration from bone marrow during bacterial infection requires signals mediated by chemokine receptor CCR2. Nat Immunol 7, 311-317 (2006).

36. Robbins, C. S. et al. Local proliferation dominates lesional macrophage accumulation in atherosclerosis. Nat Med 19, 1166-1172 (2013).

37. Goldmann, T. et al. A new type of microglia gene targeting shows TAK1 to be pivotal in CNS autoimmune inflammation. Nat Neurosci 16, 1618-1626 (2013).

38. Foudi, A. et al. Analysis of histone 2B-GFP retention reveals slowly cycling hematopoietic stem cells. Nat Biotechnol 27, 84-90 (2009).

39. Mildner, A. et al. Microglia in the adult brain arise from Ly-6ChiCCR $2+$ monocytes only under defined host conditions. Nat Neurosci 10, 1544-1553 (2007).

40. Ajami, B., Bennett, J. L., Krieger, C., Tetzlaff, W. \& Rossi, F. M. Local self-renewal can sustain CNS microglia maintenance and function throughout adult life. Nat Neurosci 10, 1538-1543 (2007). 
41. Sieweke, M. H. \& Allen, J. E. Beyond stem cells: self-renewal of differentiated macrophages. Science 342, 1242974 (2013).

42. Barth, M. W., Hendrzak, J. A., Melnicoff, M. J. \& Morahan, P. S. Review of the macrophage disappearance reaction. J Leukoc Biol 57, 361-367 (1995).

43. Chorro, L. et al. Langerhans cell (LC) proliferation mediates neonatal development, homeostasis, and inflammation-associated expansion of the epidermal LC network. $J$ Exp Med 206, 3089-3100 (2009).

44. Karsunky, H., Merad, M., Cozzio, A., Weissman, I.L. \& Manz, M.G. Flt3 ligand regulates dendritic cell development from Flt3 ${ }^{+}$lymphoid and myeloid-committed progenitors to Flt3 ${ }^{+}$dendritic cells in vivo. J. Exp. Med. 198, 305-313 (2003).

45. Kim, K.W., Vallon-Eberhard, A., Zigmond, E., Farache, J., Shezen, E., Shakhar, G., Ludwig, A., Lira, S.A., Jung, S. In vivo structure/function and expression analysis of the CX3C chemokine fractalkine. Blood. 118(22):e156-67 (2011).

46. Jongstra-Bilen, J., et al. Low-grade chronic inflammation in regions of the normal mouse arterial intima predisposed to atherosclerosis. J. Exp. Med. 203, 2073-2083 (2006).

47. Paulson, K.E., et al. Resident intimal dendritic cells accumulate lipid and contribute to the initiation of atherosclerosis. Circ. Res. 106, 383-390 (2010).

48. Carvalho, B.S., and Irizarry, R.A. (2010). A framework for oligonucleotide microarray preprocessing. Bioinformatics 26, 2363-2367.

49. Gautier, E.L., Shay, T., Miller, J., Greter, M., Jakubzick, C., Ivanov, S., Helft, J., Chow, A., Elpek, K.G., Gordonov, S., et al. (2012). Gene-expression profiles and transcriptional regulatory pathways that underlie the identity and diversity of mouse tissue macrophages. Nat Immunol 13, 1118-1128. 


\section{Figure 1. Phenotype and gene expression profiling of arterial macrophages. (a)}

Identification of aortic macrophages. Contour plots demonstrate gating scheme for $\mathrm{F} 4 / 80^{+} \mathrm{CD} 11 \mathrm{~b}^{+}$aortic macrophages, $\mathrm{F} 4 / 80^{10} \mathrm{CD} 11 \mathrm{c}^{+} \mathrm{MHCII}^{+}$dendritic cells (DC) and Ly6C ${ }^{\text {hi/lo }} \mathrm{F} 4 / 80^{10} \mathrm{CD} 64^{+}$monocytes in 6-8 week old C57BL6/J mice (mean $\left.\pm \mathrm{SEM} ; \mathrm{n}=15\right)$. (b) Principal component analysis of whole genome microarray data from isolated arterial macrophages, compared to macrophages and DC populations collected by the Immunological Genome Project (GSE15907). For arterial macrophages, expression data are pooled from 3 independent experiments. (c) Heat map of mRNA transcripts increased in arterial macrophages by fivefold or more relative to their expression in microglia, splenic red pulp macrophages, and alveolar macrophages. (d) Heat map of mRNA transcripts decreased in arterial macrophages by fivefold or more relative to their expression in the remaining 3 macrophage populations. (e) Flow cytometry analysis of cell surface markers expressed by arterial macrophages, Kupffer cells, alveolar macrophages, and microglia (filled histograms). Open histograms = isotype controls. (f) Zbtb46-GFP expression in macrophages (filled histograms) and DC (open histograms) from aorta, liver, lung, and brain of $Z b t b 46^{\mathrm{gfp} /+}$ mice. One experiment of two is shown. Dashed lines $=$ wild type macrophages $\left(\mathrm{GFP}^{-}\right)$, dotted lines $=$wild type $\mathrm{DC}\left(\mathrm{GFP}^{-}\right) .(\mathbf{g}) C D 11 c$-eYPF expression in arterial macrophages and DC from $C D 11 c^{\mathrm{eYFP} /+}$ mice. Data show one of 3 animals examined (h) Flow cytometry analysis of arterial macrophages in adventitial and intima/media compartments (mean \pm SEM; adventitia $\mathrm{n}=27$, intima/media $\mathrm{n}=22$ ). Data show individual animals pooled from 4 independent experiments. ${ }^{*} P<0.0001$ (unpaired $t$-test). (i) Enumeration of arterial macrophages from $(h)($ mean \pm SEM; adventitia $n=27$, intima/media $n=22)$. Data show individual animals pooled from 4 independent experiments. $* P<0.0001$ (unpaired Student's $t$-test). (j) CD68 staining of adventitia and intima/media from ascending, descending, thoracic, and abdominal aortic segments (mean $\pm \mathrm{SD} ; \mathrm{n}=3$ ). * total aorta $P<0.0001$, ascending arch $P=0.0006$, descending arch $P<0.0001$, thoracic $P<0.0001$, abdominal $P<0.0003$ (unpaired $t$-test). Data show individual mice pooled from one experiment.

Figure 2. Arterial macrophages have embryonic and postnatal origins. (a) Phenotypic analysis of arterial macrophages before and after birth. Dot plots show representative F4/80 and CD11b staining at multiple ages. (b) Macrophage accumulation over time expressed as a percentage of total $\mathrm{CD}_{4} 5^{+}$leukocytes $(\mathrm{n}=31)$. Data show individual mice analyzed at multiple 
time points. $P=0.0051$ (linear regression analysis). (c) Major histocompatibility (MHC) II expression on arterial macrophages over time $(\mathrm{n}=34)$. Data show individual mice analyzed at multiple time points. $P<0.0001$ (linear regression analysis). (d) E8.5-induced $\mathrm{CX}_{3} \mathrm{CR} 1-\mathrm{Td}^{\mathrm{T}}{ }^{\text {Tomato }}$ expression in $\mathrm{F} 4 / 80^{\text {high }} \mathrm{CD} 11 \mathrm{~b}^{\text {low }}$ and $\mathrm{F} 4 / 80^{\text {int }} \mathrm{CD} 11 \mathrm{~b}^{\text {high }}$ arterial macrophages at $\mathrm{E} 16.5$ (mean \pm $\mathrm{SD} ; \mathrm{n}=6$ ). Data show a representative histogram from one of 6 mice analyzed. (e) Representative histograms illustrating E8.5-induced $\mathrm{CX}_{3} \mathrm{CR} 1-\mathrm{Td}^{\text {Tomato }}$ expression in arterial macrophages at DOB and 10 weeks of age. (f) Time course of E8.5-induced $\mathrm{CX}_{3} \mathrm{CR} 1-\mathrm{Td}^{\text {Tomato }}$ expression in arterial macrophages and Kupffer cells normalized to $\mathrm{CX}_{3} \mathrm{CR} 1-\mathrm{Td}^{\text {Tomato }}$ expression in brain microglia (mean \pm SD; E16.5 $n=6$, DOB $n=7$, PND3 $n=1$, PND13 $n=3$, PND50 $n=$ 3, PND70 $\mathrm{n}=2$ ). (g) Identification of FLT3-Cre ${ }^{+}\left(\mathrm{GFP}^{+}\right)$macrophages (aorta) in newborn (DOB) Flt ${ }^{\text {cre }} \times \operatorname{Rosa}^{\mathrm{mT} / \mathrm{mG}}$ reporter mice (mean $\pm \mathrm{SEM} ; \mathrm{n}=9$ ). Data show representative histograms from one of 9 mice examined. (h) $\mathrm{CX}_{3} \mathrm{CR} 1-\mathrm{Td}^{\text {Tomato }}$ expression in macrophages isolated from aorta, liver (Kupffer cells), lung (alveolar macrophages), and peritoneum normalized to $\mathrm{CX}_{3} \mathrm{CR} 1-\mathrm{Td}^{\text {Tomato }}$ expression in brain microglia. Macrophages isolated from mice at PND50 (mean $\pm \mathrm{SD} ; \mathrm{n}=3$ mice per tissue). (i) $\mathrm{CX}_{3} \mathrm{CR} 1-\mathrm{Td}^{\mathrm{Tomato}}$ expression in $\mathrm{MHCII}^{-}$and $\mathrm{MHCII}^{+}$arterial macrophages from mice at PND50 (mean $\pm \mathrm{SD} ; \mathrm{n}=3$ ). (j) Immunofluorescence (IF) showing $\mathrm{GFP}^{+}$YS-derived arterial macrophages in aortic adventitia of adult $C s f 1 r^{\text {MeriCreMer }} \mathrm{x}$ $R o s a^{\mathrm{mTmG}}$ mice administered TAM at E8.5. Shown is a representative image from one of 3 animals examined. (k) Representative histograms illustrating $\mathrm{CX}_{3} \mathrm{CR} 1-\mathrm{Td}^{\text {Tomato }}$ expression in arterial macrophages of neonatal (PND2) and adult mice administered TAM at E18.5. (l) E18.5induced $\mathrm{CX}_{3} \mathrm{CR} 1-\mathrm{Td}^{\text {Tomato }}$ expression in arterial macrophages, circulating Ly6 $\mathrm{C}^{\text {high }}$ monocytes, and microglia over time (mean \pm SD; DOB $n=1, \operatorname{PND} 2 n=3$, PND3 $n=2$, PND14 $n=4$, PND35 $n=2$, PND $43 n=2$ ). (m) MCP-1 and VCAM-1 expression detected by RT-PCR and conducted on aortic tissue taken from mice at indicated time points (mean $\pm \mathrm{SD} ; \mathrm{n}=4$ mice per time point except $\mathrm{t}=1$ where $\mathrm{n}=3$ ). ${ }^{*} P<0.05$ (unpaired $t$-test). (n) Identification of FLT3-Cre ${ }^{+}$ $\left(\mathrm{GFP}^{+}\right.$) monocytes (blood) and macrophages (aorta) in adult $\mathrm{Flt}^{\mathrm{cre}}{ }^{\mathrm{x}} \mathrm{Ros}{ }^{\mathrm{mT} / \mathrm{mG}}$ reporter mice (mean $\pm \mathrm{SD} ; \mathrm{n}=3$ ). Data show representative histograms from one of 3 mice examined. (o) Representative IF imaging from animals in (o) showing co-localization of FLT3-Cre recombination (GFP) and CD68 (Texas Red) in aortic adventitia of adult Flt ${ }^{\text {cre }} \times$ Rosa $^{\mathrm{mT} / \mathrm{mG}}$ reporter mice. 
Figure 3. $\mathrm{CX}_{3} \mathrm{CL1}-\mathrm{CX}_{3} \mathrm{CR} 1$ interactions determine survival of arterial macrophages. (a) IF showing GFP staining in aortic adventitia of $C X_{3} C R 1^{\mathrm{gfp} /+}$ mice. Shown is a representative image from one of 3 animals examined. (b) Dot plots show GFP staining is mainly limited to CD45 arterial macrophages in aortae of $C X_{3} C R 1^{g f p /+}$ mice. (c) Representative histogram shows $\sim 70 \%$ of $\mathrm{F} 4 / 80^{+} \mathrm{CD} 11 \mathrm{~b}^{+}$arterial macrophages express $C X_{3} C R 1$ (mean $\pm \mathrm{SD} ; \mathrm{n}=3$ ). (d) CD68 staining of aortic adventitia in wild type and $C X_{3} C R 1^{-/-}$mice. Data show individual mice pooled from one experiment (mean $\pm \mathrm{SEM} ; \mathrm{n}=7$ ). ${ }^{*} P<0.0001$ (unpaired $t$-test). (e) Enumeration of arterial macrophages in wild type and $C X_{3} C R 1^{-/-}$mice by flow cytometry. Data show individual mice pooled from 3 independent experiments (mean $\pm \mathrm{SEM}$; wild type $\mathrm{n}=15, C X_{3} C R 1^{-/-}$mice $\mathrm{n}=$ 14). ${ }^{*} P=0.045$ (unpaired $t$-test). (f) Arterial macrophage abundance in mice following antibodymediated neutralization of $\mathrm{CX}_{3} \mathrm{CL} 1$. Data show individual mice pooled from two independent experiments (mean $\pm \mathrm{SEM}$, isotype $\mathrm{n}=11$, anti-CX ${ }_{3} \mathrm{CL} 1 \mathrm{n}=12$ ). ${ }^{*} P=0.042$ (unpaired $t$-test). (g) Percentage of aortic macrophages from wild type and $C X_{3} C R 1^{-1-}$ mice in $\mathrm{S}$ and $\mathrm{G}_{2} / \mathrm{M}$ phases of the cell cycle (mean $\pm \mathrm{SD}$; wild type $\mathrm{n}=4, C X_{3} C R 1^{-/-} \mathrm{n}=5$ ). Data show individual mice pooled from one experiment. $P=0.09$ (unpaired $t$-test). (h) Percentage of aortic macrophages expressing Fas in wild type and $C X_{3} C R I^{-1-}$ mice (mean $\pm \mathrm{SEM}, \mathrm{n}=7$ ). Data show individual mice pooled from one experiment. $* P=0.0083$ (unpaired $t$-test). (i) Enumeration of $\mathrm{TUNEL}^{+} \mathrm{CD} 8^{+}$cells in aortic adventitia of wild type and $C X_{3} C R 1^{-/-}$mice (mean $\left.\pm \mathrm{SEM}, \mathrm{n}=7\right)$. $* P<0.0001$ (unpaired $t$-test). (j) IF showing association of adventitial aortic macrophages $\left(\mathrm{CD}^{+} 8^{+}\right)$with $\mathrm{CX}_{3} \mathrm{CL}^{+}$cells in $\mathrm{CX}_{3} \mathrm{CL} 1^{\text {cherry }}$ mice. Shown is a representative image from one of several mice examined. (k) Representative dot plots showing arterial expression of $\mathrm{CX}_{3} \mathrm{CL}_{1}$ in $\mathrm{CD} 45^{-}$PDGFR $\alpha^{+}$and $\mathrm{CD} 45^{-} \mathrm{CD} 31^{+}$cells. 3 animals were analyzed (mean $\pm \mathrm{SD}$ ). (l) IF showing localization of $\mathrm{CX}_{3} \mathrm{CL} 1$ and either $\mathrm{CD} 31^{+}$or $\mathrm{PDGFR}^{+}$cells. Shown are representative images from one of 3 animals examined.

Figure 4. Arterial macrophages are maintained independent of monocytes in adulthood. (a) Enumeration of aortic macrophages in wild type (WT) and $C C R 2^{-/-}$mice (mean $\pm \mathrm{SEM}$; wild type $\left.\mathrm{n}=6, C C R 2^{-/-} \mathrm{n}=5\right)$. Data show individual mice pooled from two independent experiments. $P=0.79$ (unpaired $t$-test). (b) Wild type and GFP mice were joined in parabiosis for 8 months. Data show Ly-6C ${ }^{\text {high }}$ and Ly-6C ${ }^{\text {low }}$ monocyte chimerism in the blood, and macrophage chimerism in the aorta, heart, lung, and liver. For monocytes, data show individual 
mice pooled from 6 pairs of parabionts. For macrophages, data show individual mice pooled from 2 pairs of parabionts (mean \pm SEM; monocytes $\mathrm{n}=12, \mathrm{M} \Phi \mathrm{n}=4)$. (c) GFP and $C C R 2^{-/-}$ mice were joined in parabiosis for 6 weeks. Data show monocyte chimerism in the blood, and macrophage chimerism in the aorta, heart, lung, and liver. Data show individual animals pooled from 1 pair of parabionts (mean $\pm \mathrm{SD} ; \mathrm{n}=2$ ). (d) Relative contribution of local renewal and monocyte recruitment to macrophage accumulation over 8 months. (e) Representative histograms showing $\mathrm{CX}_{3} \mathrm{CR} 1-\mathrm{Td}^{\text {Tomato }}$ expression in arterial macrophages 1 week and 9-11 months following TAM exposure (mean $\pm \mathrm{SD}$; 1 week $\mathrm{n}=3,9$ months $\mathrm{n}=2,11$ months $\mathrm{n}=1$ ). (f) Adult TetOP-H2B-GFP mice were administered doxycycline for 4 weeks to induce H2B-GFP expression and then loss of fluorescence in aortic macrophages (indicative of cell division) was monitored during a 2 month chase period (mean $\pm \mathrm{SD} ; \mathrm{n}=4$ ). (g) Mathematical model predicts rate of loss of $\mathrm{GFP}^{+}$macrophages over time (see Methods). (h) 5-bromodeoxyuridine (BrdU) incorporation by aortic macrophages (mean $\pm \mathrm{SD} ; \mathrm{n}=5$ ). Data show individual animals pooled from one experiment.

Figure 5. Arterial macrophages self renew following exposure to bacteria. (a) Bone marrow chimeras were generated by reconstituting lethally irradiated CD $45.2^{+}$mice with $\mathrm{CD} 45.1^{+}$bone marrow cells. Data show chimerism in blood CD $45^{+}$leukocytes and macrophages in the heart, lung (alveolar), aorta, liver (Kupffer cells), and brain (microglia) (mean $\pm \mathrm{SD} ; \mathrm{n}=3$ ). (b) Enumeration of Ly6 $\mathrm{C}^{\text {high }}$ monocytes, CD $115^{+}$macrophages (resident), CD115 $5^{-}$macrophages (bone marrow monocyte-derived), and resident macrophages in $C C R 2^{-1-}$ mice following exposure to LPS. Data were collected at multiple time points (mean $\pm \mathrm{SD}$; day $0 \mathrm{n}=8,4 \mathrm{~h} n=3$, $12 \mathrm{~h} \mathrm{n}=3,24 \mathrm{hn}=3,72 \mathrm{~h} \mathrm{n}=4,120 \mathrm{~h} \mathrm{n}=4,336 \mathrm{~h} \mathrm{n}=3,648 \mathrm{~h} \mathrm{n}=3$ ). (c) Dot plots from CD45.1 ${ }^{+}$ parabiont demonstrating chimerism in CD $115^{+}$Lyve- $1^{+}$and CD115 Lyve- $1^{-}$macrophages. Data show a representative CD45.1 partner. (d) Wild type and GFP mice were joined in parabiosis for 6 weeks. Mice were either injected with lipopolysaccharide (LPS) or subjected to cecal puncture. Data show chimerism in blood monocytes and aortic macrophages 7 days following bacterial exposure (mean $\pm \mathrm{SD} ; \mathrm{n}=4$ ). Data show individual mice pooled from 2 pairs of parabionts. (e) IF showing CD68 staining in adventitia and intima of aorta 7 days following exposure to LPS. Shown is a representative image from one of 4 animals examined. (f) Number of aortic macrophages in $\mathrm{S}$ and $\mathrm{G}_{2} / \mathrm{M}$ phases of the cell cycle 5 days after LPS administration. Data show 
individual mice pooled from one experiment (mean $\pm \mathrm{SD}, \mathrm{n}=6$ ). ${ }^{*} P=0.0026$ (unpaired $t$-test). (g) Mice were exposed to LPS and injected with flow-sorted Ly6 $\mathrm{C}^{\text {high }}$ bone marrow monocytes. At the indicated time points following LPS exposure, the percentage of $\mathrm{CD} 115^{+}$(resident) and $\mathrm{CD} 115^{-}$(bone marrow monocyte-derived) macrophages that were $\mathrm{GFP}^{+}$is reported. Data show that monocytes give rise to $\mathrm{CD} 115^{-}$, but not $\mathrm{CD} 115^{+}$macrophages (mean $\pm \mathrm{SD}$; day $0 \mathrm{n}=8$, $4 \mathrm{~h} \mathrm{n}$ $=3,12 \mathrm{~h} \mathrm{n}=3,24 \mathrm{~h} \mathrm{n}=3,72 \mathrm{~h} \mathrm{n}=4,240 \mathrm{~h} \mathrm{n}=4,648 \mathrm{~h} \mathrm{n}=3$ ). (h) $\mathrm{CD} 115^{-}$and CD115 macrophages were assessed for their in vivo capacity to phagocytose pHrodo ${ }^{\mathrm{TM}}$ E. coli BioParticles ${ }^{\circledR} 12 \mathrm{~h}$ following exposure to LPS. Data demonstrate that bacteria are taken up by $\mathrm{CD} 115^{-}$macrophages (mean $\pm \mathrm{SEM} ; \mathrm{n}=5$ ). Dot plots show representative images from one animal of 5. Two independent experiments were performed. (i) E8.5-induced $\mathrm{CX}_{3} \mathrm{CR} 1-\mathrm{Td}^{\mathrm{Tomato}}$ expression in arterial macrophages 7 days after either LPS administration or induction of sepsis by cecal puncture. Data show individual mice pooled from two independent experiments (mean \pm SEM, control $n=5$, LPS $n=5$, sepsis $n=4)$. (j) Volcano plot demonstrating gene expression changes in aortic macrophages before and after sepsis. Of 10391 genes analyzed, only 10 genes were up-regulated (red) and 2 genes down-regulated (blue) in macrophages from mice subjected to cecal puncture ( $\mathrm{n}=3$ independently collected samples per experimental group). 
Figure 1. Phenotype and gene expression profiling of arterial macrophages.

a
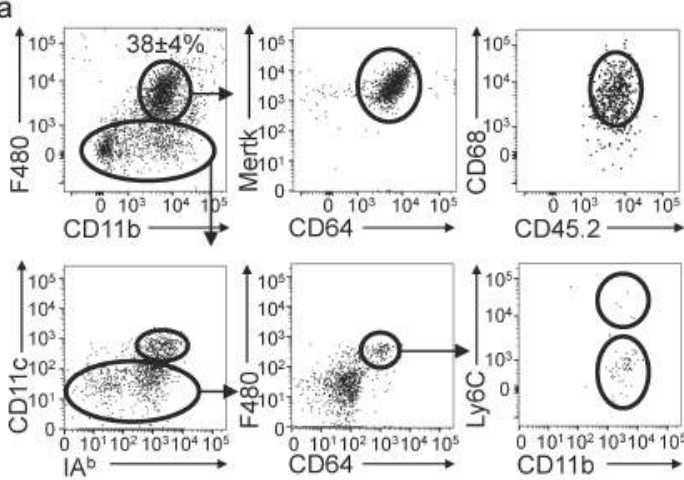

b
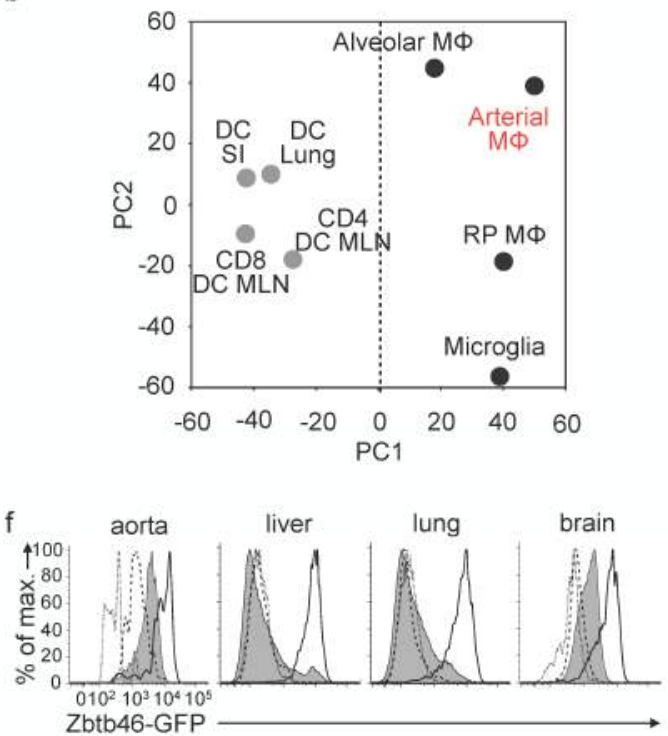

g

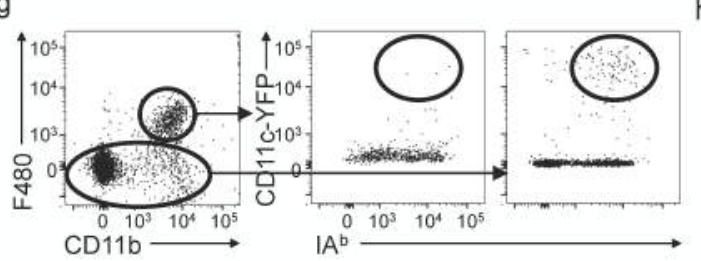

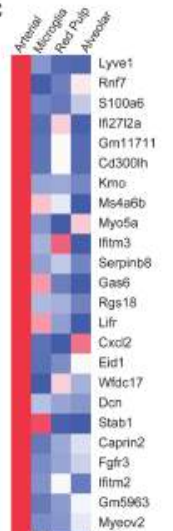
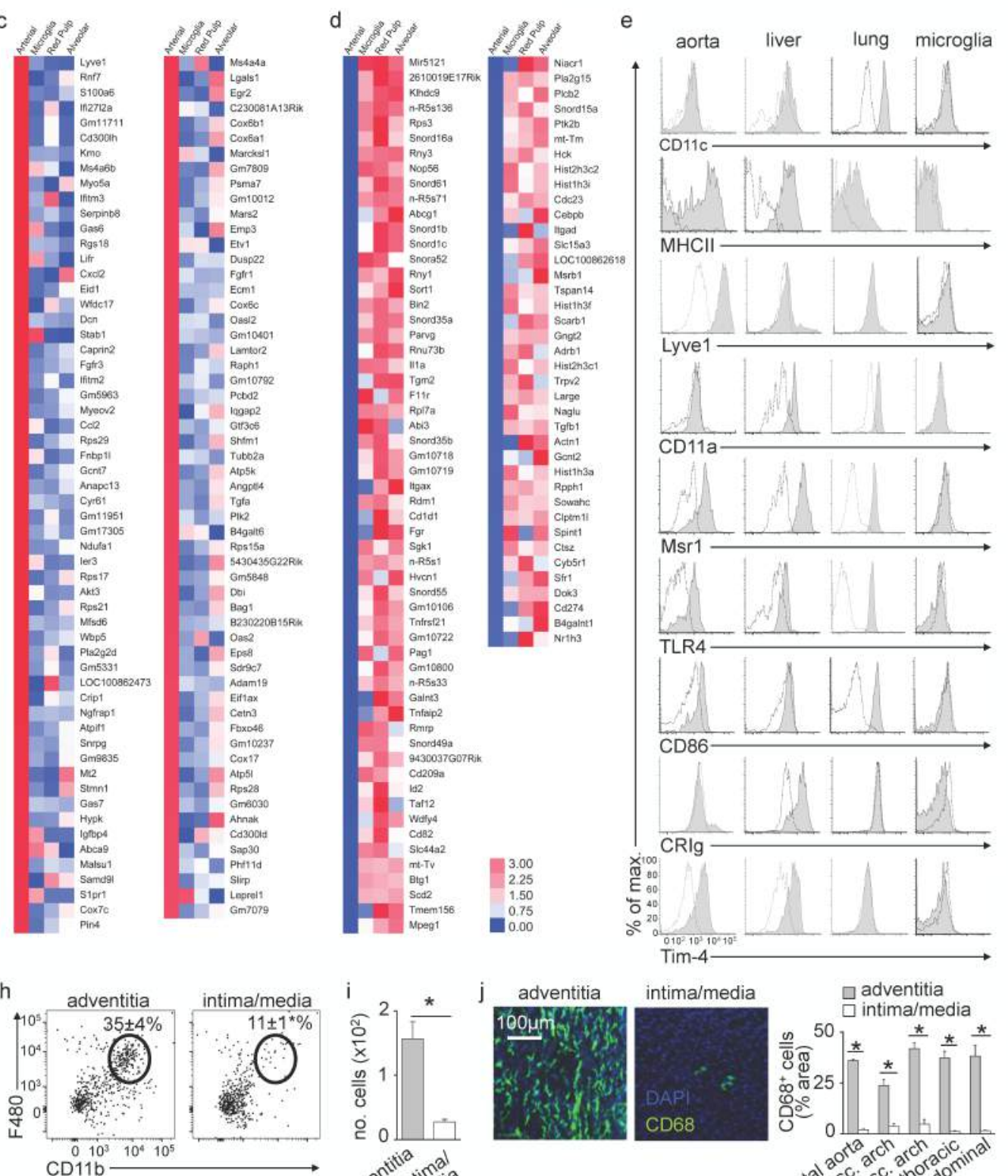

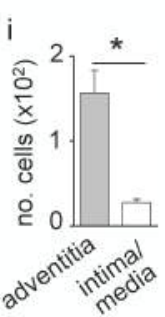

intima/media
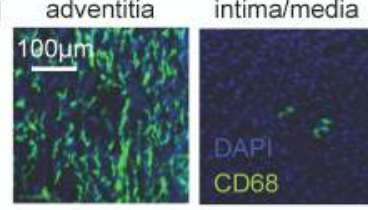

$\square$ adventitia

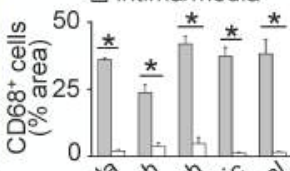

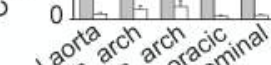

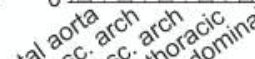


Figure 2. Arterial macrophages have embryonic and postnatal origins.

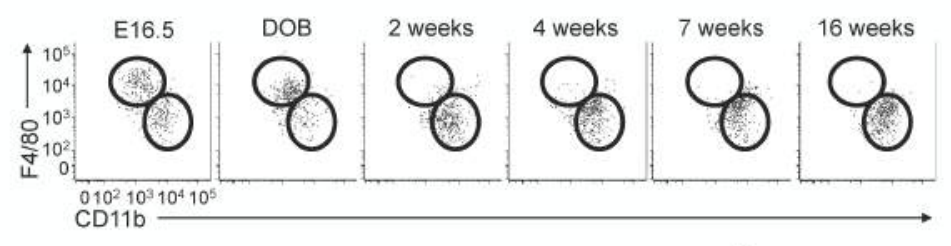

b

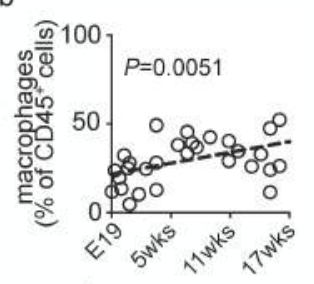

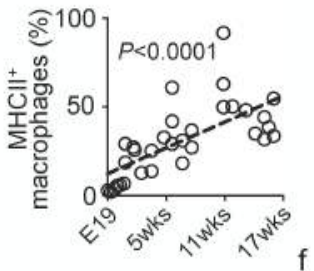
e $\frac{\text { TAM E8.5 }}{\text { brain }}$ DOB $\frac{\text { wt }}{\text { aorta }} \frac{1}{\text { brain }} 10$ weeks $\frac{}{\text { aorta }}$

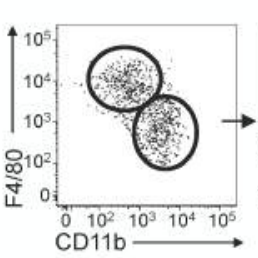

$\mathrm{F} 4 / 80^{\text {hi }} \mathrm{CD} 11 \mathrm{~b}^{\mathrm{b}} \mathrm{F} 4 / 80^{\mathrm{int}} \mathrm{CD} 11 \mathrm{~b}^{\text {hi }}$
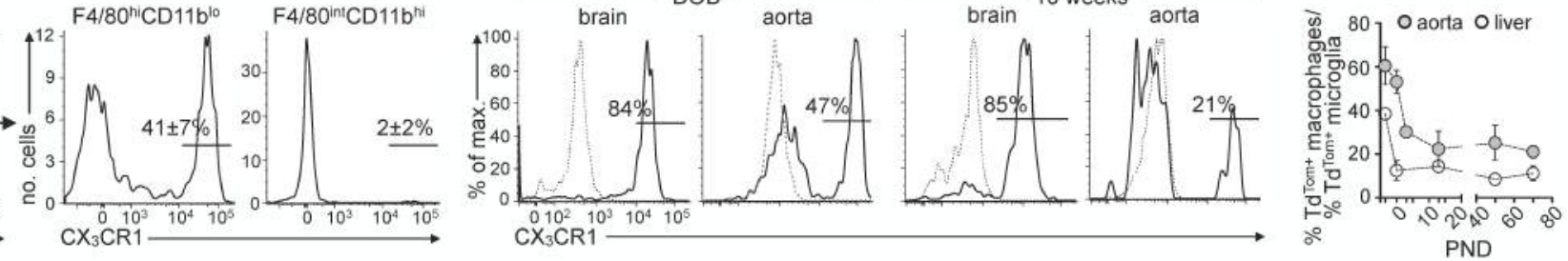

g $\mathrm{h}$
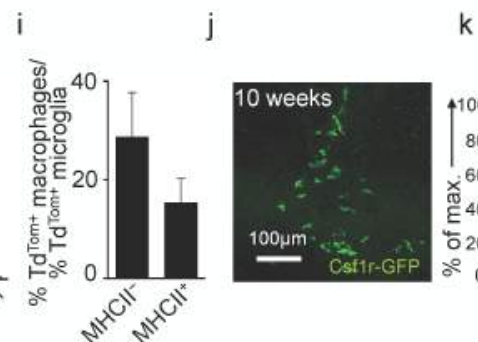

k
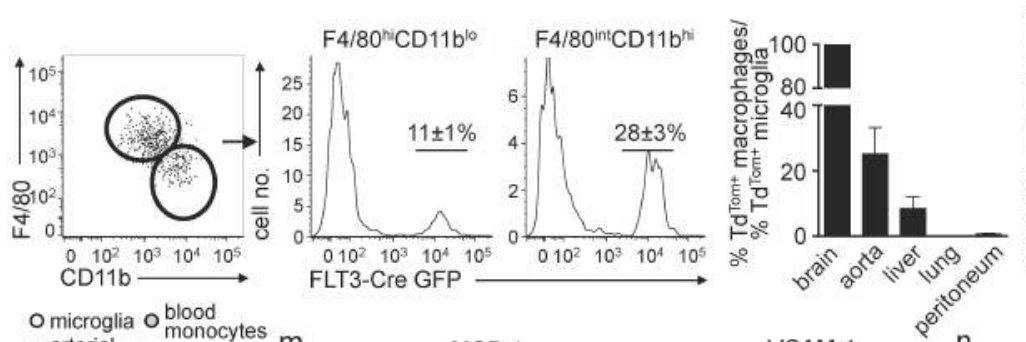

O microglia O monocy

$\checkmark$ macrophages
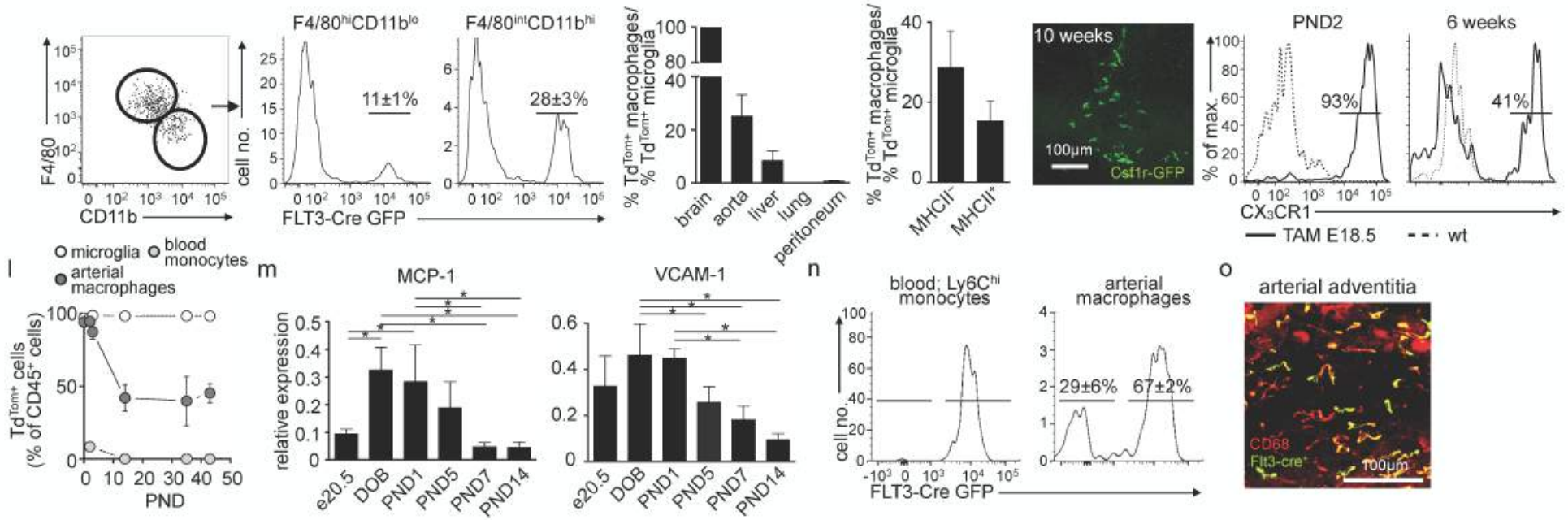
Figure 3. $\mathrm{CX}_{3} \mathrm{CL1}-\mathrm{CX}_{3} \mathrm{CR} 1$ interactions determine survival of arterial macrophages.

a

b

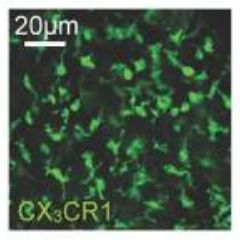

C

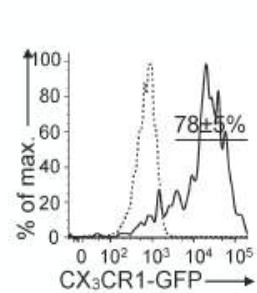

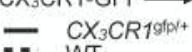
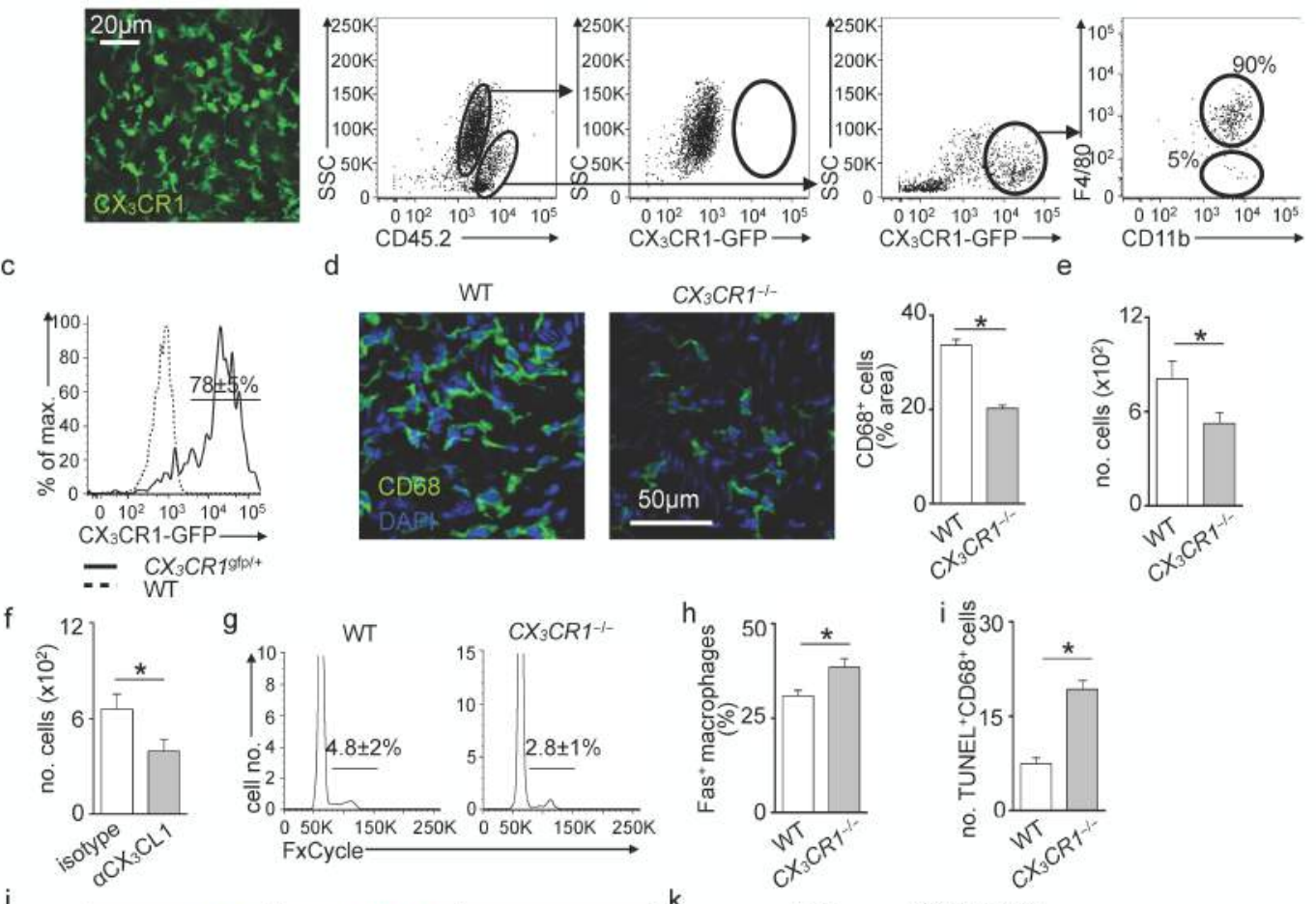

C
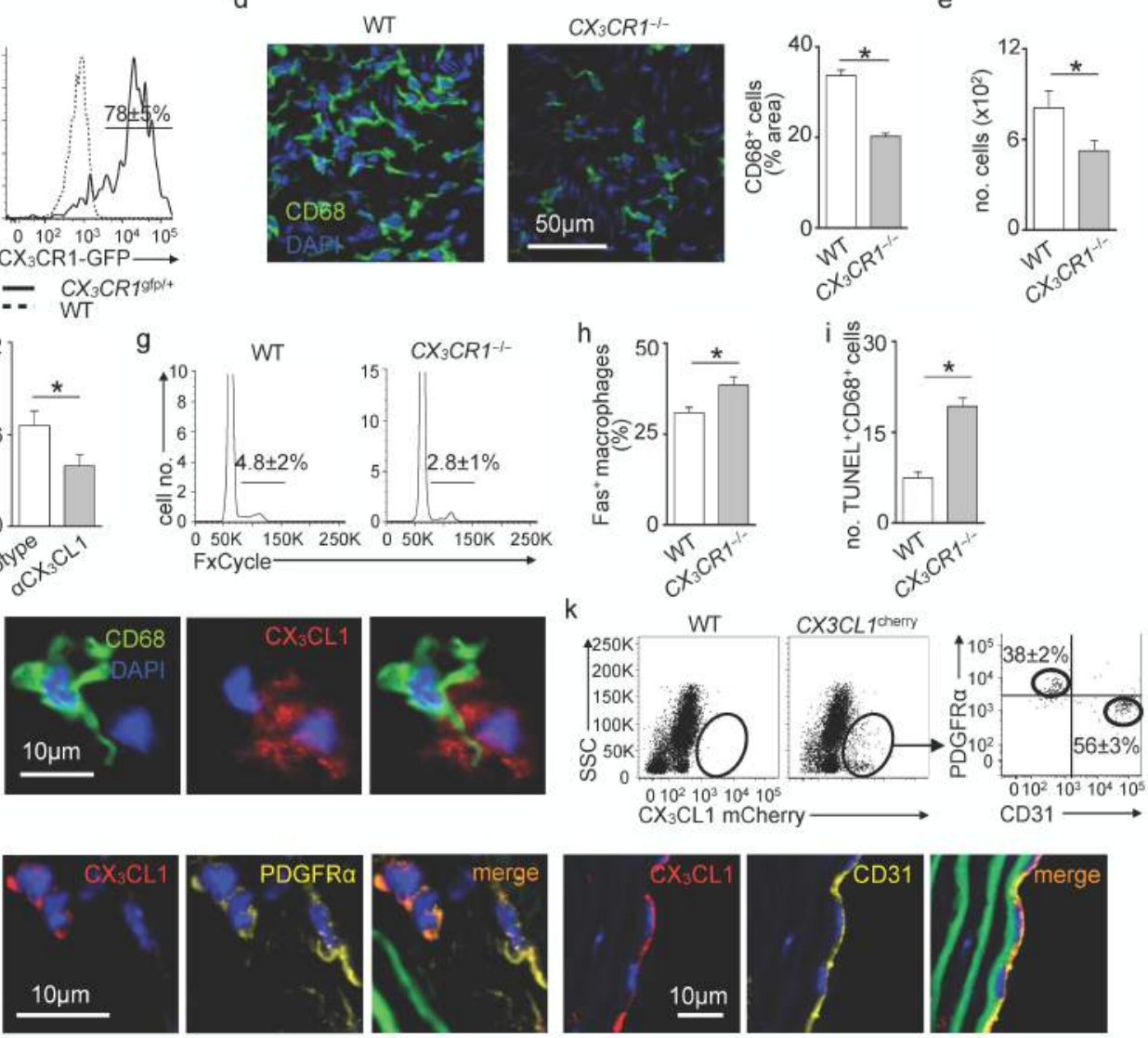
Figure 4. Arterial macrophages are maintained independent of monocytes in adulthood.

a

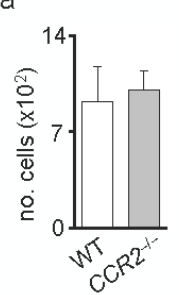

b

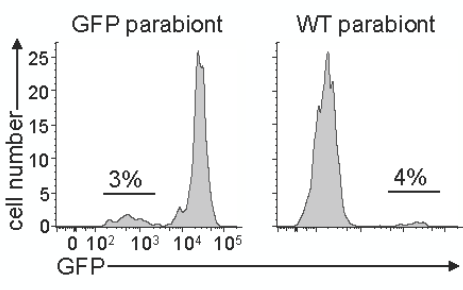

e

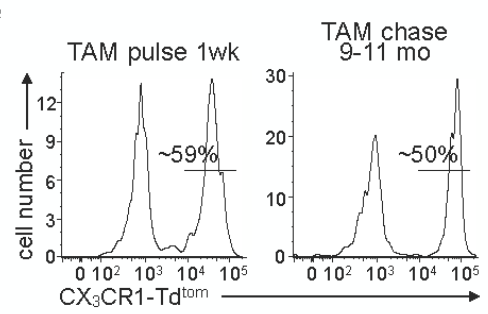

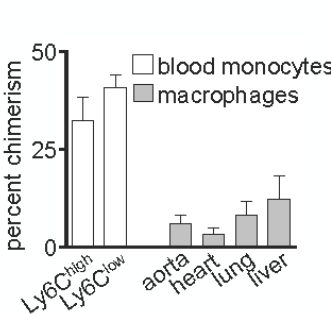

f

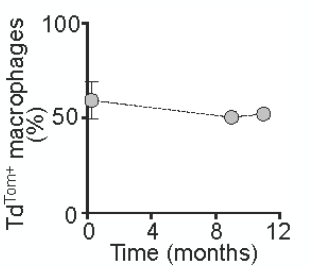

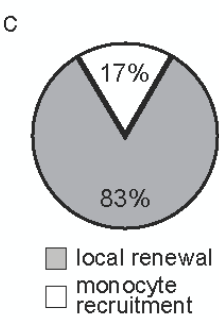

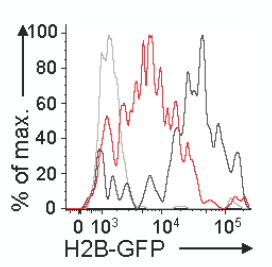

- no DOX d

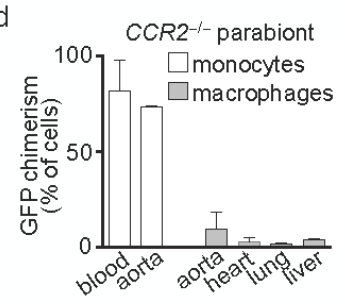

g
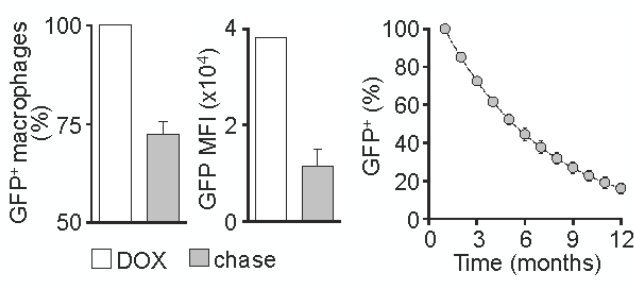

h

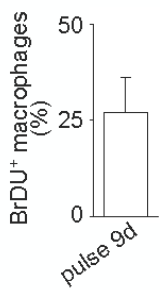


Figure 5. Arterial macrophages self renew following exposure to bacteria.

a

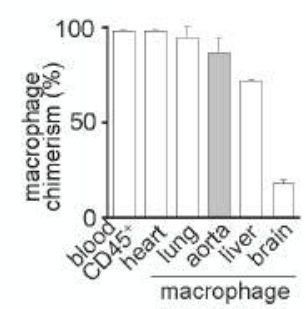

C

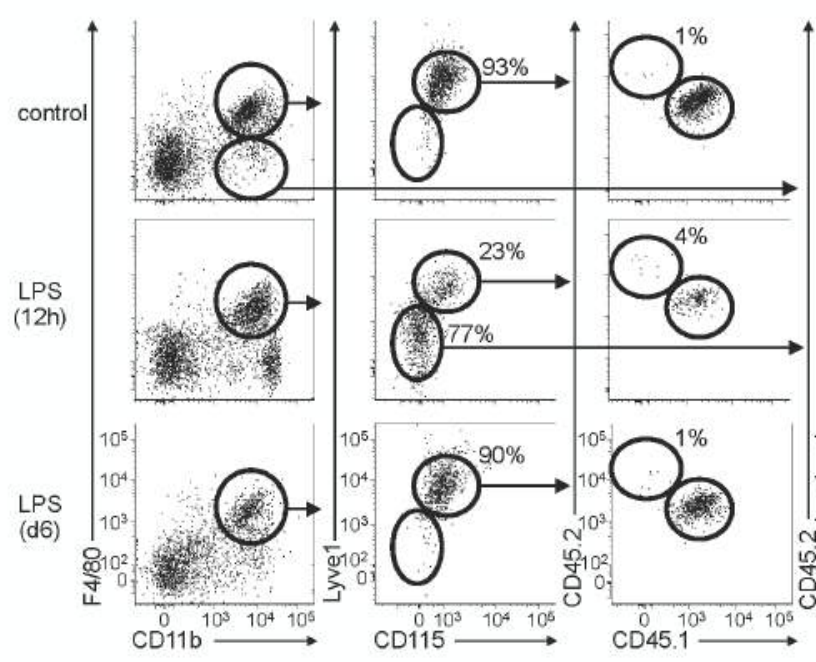

b

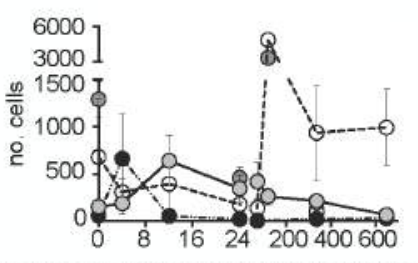

OCD 115* macrophages OCCR2-1- macrophages
OCD115- macrophages 1 Ly6Chi monocytes

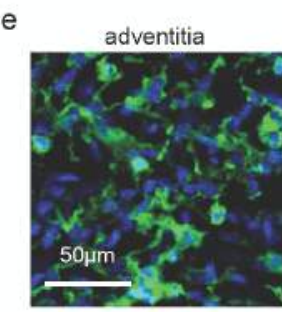

d
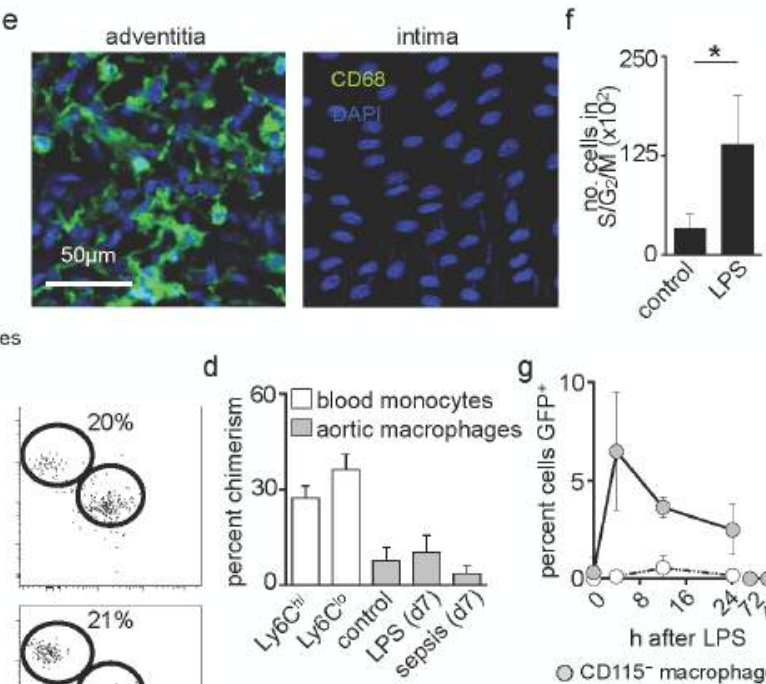

g
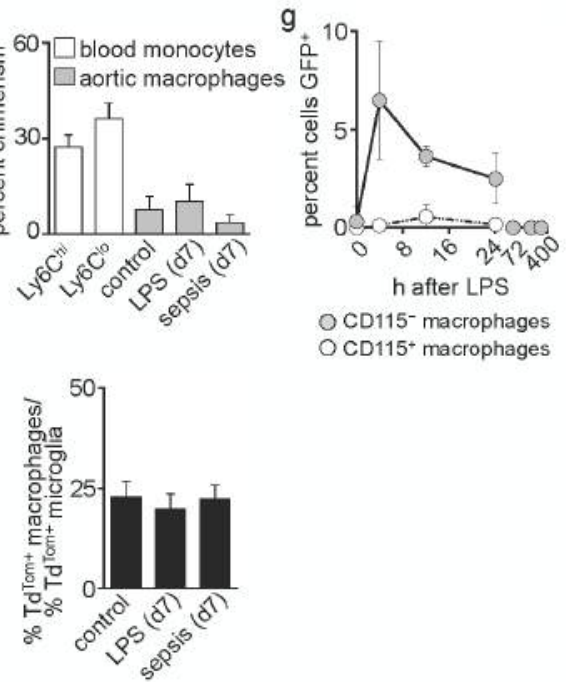

h
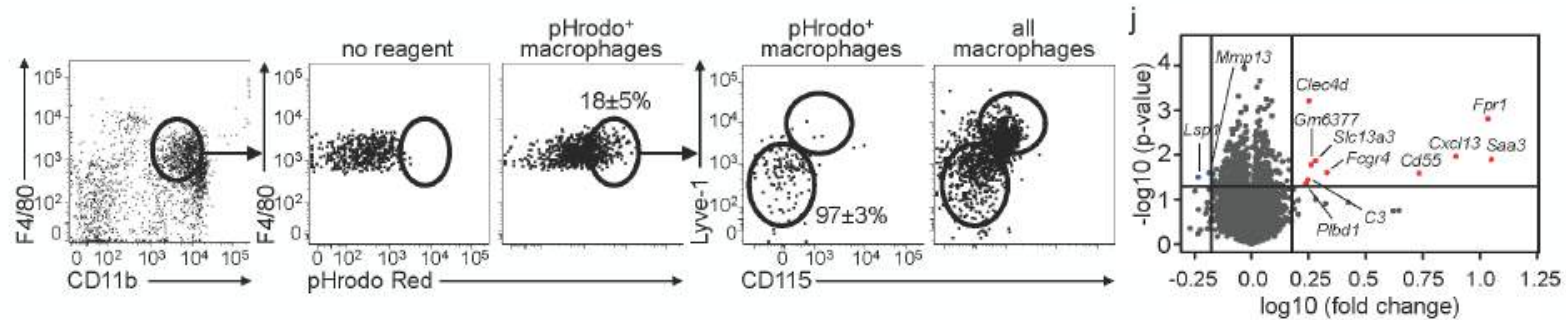